\title{
Autoreceptor control of serotonin dynamics
}

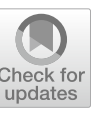

\author{
Janet Best ${ }^{1}$, William Duncan ${ }^{2}$, Farrah Sadre-Marandi ${ }^{3}$, Parastoo Hashemi ${ }^{4}$, H. Frederik Nijhout $^{5}$ \\ and Michael Reed ${ }^{2^{*}}$ (1)
}

\begin{abstract}
Background: Serotonin is a neurotransmitter that has been linked to a wide variety of behaviors including feeding and body-weight regulation, social hierarchies, aggression and suicidality, obsessive compulsive disorder, alcoholism, anxiety, and affective disorders. Full understanding involves genomics, neurochemistry, electrophysiology, and behavior. The scientific issues are daunting but important for human health because of the use of selective serotonin reuptake inhibitors and other pharmacological agents to treat disorders. This paper presents a new deterministic model of serotonin metabolism and a new systems population model that takes into account the large variation in enzyme and transporter expression levels, tryptophan input, and autoreceptor function.

Results: We discuss the steady state of the model and the steady state distribution of extracellular serotonin under different hypotheses on the autoreceptors and we show the effect of tryptophan input on the steady state and the effect of meals. We use the deterministic model to interpret experimental data on the responses in the hippocampus of male and female mice, and to illustrate the short-time dynamics of the autoreceptors. We show there are likely two reuptake mechanisms for serotonin and that the autoreceptors have long-lasting influence and compare our results to measurements of serotonin dynamics in the substantia nigra pars reticulata. We also show how histamine affects serotonin dynamics. We examine experimental data that show very variable response curves in populations of mice and ask how much variation in parameters in the model is necessary to produce the observed variation in the data. Finally, we show how the systems population model can potentially be used to investigate specific biological and clinical questions.

Conclusions: We have shown that our new models can be used to investigate the effects of tryptophan input and meals and the behavior of experimental response curves in different brain nuclei. The systems population model incorporates individual variation and can be used to investigate clinical questions and the variation in drug efficacy. The codes for both the deterministic model and the systems population model are available from the authors and can be used by other researchers to investigate the serotonergic system.
\end{abstract}

Keywords: Serotonin, Autoreceptor, Mathematical model

\section{Background}

In 2010, three of the authors (JB, HFN, MCR) created a mathematical model of serotonin synthesis in varicosities, storage in vesicles, release into the extracellular space, reuptake by serotonin transporters (SERTs), and control by serotonin autoreceptors [1]. In subsequent

\footnotetext{
*Correspondence: reed@math.duke.edu

2 Department of Mathematics, Duke University, Durham, NC 27708, USA

Full list of author information is available at the end of the article
}

years, they used the model to study and evaluate various hypotheses about serotonergic function including connections with dopaminergic signaling $[2,3]$, bursts in the dorsal raphe nucleus (DRN) [4], the effects of serotonin on levodopa therapy [5], and serotonin dynamics in the basal ganglia [6]. In 2013, they began a collaboration with Parastoo Hashemi, an electrochemist who can measure serotonin and histamine in the extracellular space in vivo in various brain regions of the mouse after stimulation of the DRN. This collaboration led to new insights into

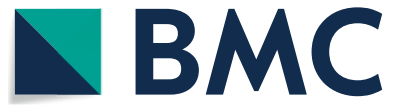

(c) The Author(s) 2020. This article is licensed under a Creative Commons Attribution 4.0 International License, which permits use, sharing, adaptation, distribution and reproduction in any medium or format, as long as you give appropriate credit to the original author(s) and the source, provide a link to the Creative Commons licence, and indicate if changes were made. The images or other third party material in this article are included in the article's Creative Commons licence, unless indicated otherwise in a credit line to the material. If material is not included in the article's Creative Commons licence and your intended use is not permitted by statutory regulation or exceeds the permitted use, you will need to obtain permission directly from the copyright holder. To view a copy of this licence, visit http://creativeco mmons.org/licenses/by/4.0/. The Creative Commons Public Domain Dedication waiver (http://creativecommons.org/publicdomain/ zero/1.0/) applies to the data made available in this article, unless otherwise stated in a credit line to the data. 
serotonergic function [7-9]. It also revealed that various aspects of the 2010 model were naive and too simplistic. This paper presents a new, substantially different, revised model.

In the experiments in the Hashemi Lab, the medial forebrain bundle (MFB) is stimulated for $2 \mathrm{~s}$ and the antidromic spikes excite the DRN. The DRN sends bursts of action potentials to projection regions such as the substantia nigra pars reticulata ( $\mathrm{SNr}$ ), the pre-frontal cortex (PFC), and the hippocampus (HC). Serotonin rises rapidly in the extracellular space in the projection regions and then typically plunges substantially below basal levels within $30 \mathrm{~s}$ [7]. This almost certainly is because inhibition of release by the autoreceptor continues well after the serotonin concentration in the extracellular space has returned to basal levels. In our 2010 model, the autoreceptor effect was modeled by high extracellular serotonin instantaneously inhibiting release, and the Hashemi experiments showed that this is wrong. In this paper, we include a full model of the cellular dynamics caused by serotonin binding to the autoreceptor, including activated receptor G-proteins and activated regulators of G-proteins. In addition, we showed in $[8,10]$ that histamine in the extracellular space inhibits the release of serotonin from serotonin varicosities. Therefore in this paper we also include a full model of a histamine $\mathrm{H}_{3}$ receptor on the serotonin varicosity that changes the dynamics of serotonin release. We also make stochastic systems population models from our deterministic model (see below) and use these systems population models to investigate certain aspects of the serotonin system.

In [7], we also showed that there are two different serotonin uptake mechanisms, SERTs that pump serotonin back into the varicosities and another uptake, which we call Uptake 2, that pumps serotonin into glial cells [1113]. The kinetics of the two uptakes are quite different and both are included in our new model. We also include the effects of serotonin binding protein (SBP) that binds serotonin tightly in vesicles but releases it quickly when the vesicles open to the extracellular space.

These are the major changes to the model, but there are many minor changes too. A schematic diagram of the model is given in Fig. 1. The pink boxes contain the acronyms of the substrates (full names are in Table 1). A complete mathematical description of the model is given in "Methods" section where we discuss in detail the major changes. The parts of the model that are similar to the 2010 model are not discussed in detail; for those parts, we refer the reader to the the 2010 paper [1] for motivation and discussion.

All individuals, whether mouse or human, are different, and the variation is important for understanding experimental results and for precision medicine. This variability is self-evident in the experimental response curves that we discuss in "Variability in response to stimulation" section. The variability comes from several sources. First, it is known that the expression levels of most enzymes vary by about $25 \%$ or more between individuals [14-16]. This means that the $V_{\max }$ values of the enzymes and transporters in the model must be assumed to vary by at least $25 \%$. Second, Fig. 1 shows a diagram of our model of serotonin dynamics in a varicosity, but the parameters for that varocisity may depend on which projection region we are looking at. Indeed, tryptophan hydroxylase (TPH) expression varies considerably between different brain regions [17], as does SERT density [18], monoamine transporter (MAT) density [19], autoreceptor density [20, 21], and monoamine oxidase (MAO) density [22]. What this means is that the deterministic model described in the Methods and indicated schematically in Fig. 1 should not be regarded as "the" model of serotonin dynamics with "correct" parameters. Rather, it is a structure, which has the major players and interactions with reasonable kinetics, that can be used to investigate and interpret experimental data and to test hypotheses.

To incorporate and utilize the biological variation we have just described, we use our deterministic model of serotonin dynamics to create systems populations models. We choose new $V_{\max }$ values for each of the enzymes and transporters in Fig. 1 by selecting independently from a uniform distribution between $75 \%$ and $125 \%$ of the normal value. We then run the model to equilibrium and record all the parameters, concentrations, and velocities at steady state. That is one virtual individual. If we do this 1000 times, we then have a database of 1000 individuals, each different from the other, and can perform the usual types of statistical analyses on the population to look for interesting aspects of population behavior. We can also vary selected subsets of the $V_{\text {max }}$ values to target specific questions and relationships. We use both the deterministic model and the systems population model throughout the Results.

In "The steady state" section, we discuss the steady state of the model and the steady state distribution of extracellular serotonin $(e h t)$ under different hypotheses on the autoreceptors. In "The effect of tryptophan input" section, we show the effect of tryptophan input on the steady state and in "The effect of meals" section the effect of meals. We use the deterministic model in "The dynamics of the autoreceptors" section to interpret experimental data on male and female mice and to illustrate the short time dynamics of the autoreceptors. In "Two serotonin uptake mechanisms and the effect of histamine" section, we use the deterministic model to understand data that show there are two uptake mechanisms and that the autoreceptors have long-lasting influence. We 


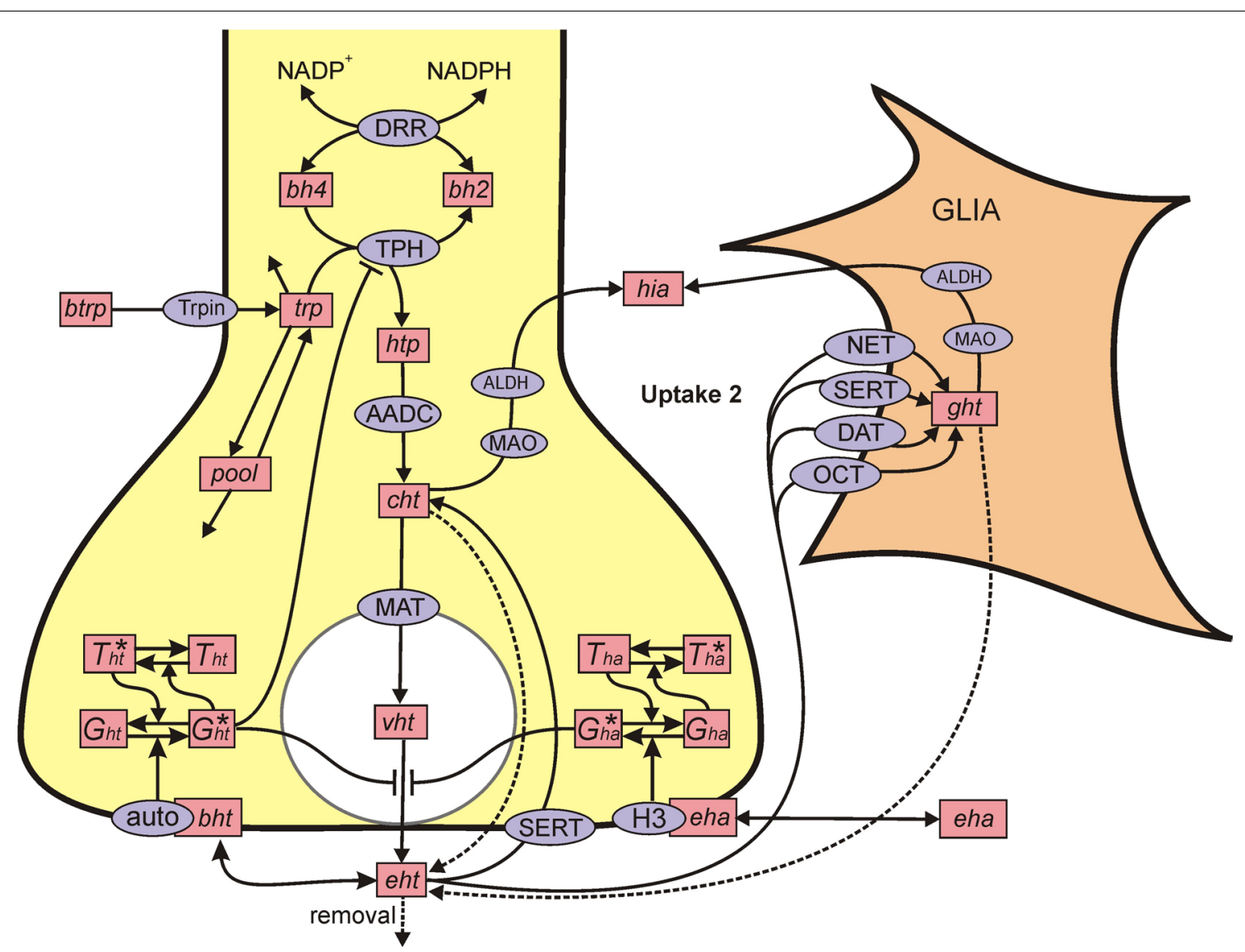

Fig. 1 Schematic diagram of the model. The figure shows the reactions in the model. The rectangular boxes indicate substrates and blue ellipses contain the acronyms of enzymes or transporters. Full names of the substrates are given in Table 1. Names of enzymes and transporters are as follows: Trpin, neutral amino acid transporter; DRR, dihydrobiopterin reductase; TPH, tryptophan hydroxylase; AADC, aromatic amino acid decarboxylase; MAT, vesicular monoamine transporter; SERT, 5-HT reuptake transporter; auto, 5-HT autoreceptors; MAO, monoamine oxidase; ALDH, aldehyde dehydrogenase; NET, norepinepherine transporter; DAT, dopamine transporter; OCT, organic cation transporter. Removal means uptake by capillaries or diffusion out of the system. The figure was created by H. F. Nijhout for this study

also show how histamine affects serotonin dynamics. In "Variability in response to stimulation" section, we examine data that shows variable response curves in populations of mice and ask how much variation in parameters in the model is necessary to produce the observed variation in the data. Finally, in "Using population models to understand drug efficacy and clinical measurements" section, we show how the systems population model can potentially be used to investigate specific biological and clinical questions.

\section{Methods}

The mathematical model consists of 16 differential equations for the variables whose full names are listed in Table 1.

In the differential equations, reaction velocities or transport velocities begin with a capital $\mathrm{V}$ followed by the name of the enzyme, the transporter, or the process as a subscript. For example, $V_{\mathrm{TPH}}\left(\operatorname{trp}, b h 4, G_{h t}^{*}\right)$ is the velocity of the tryptophan hydroxylase reaction and it depends on the concentrations of its substrates, trp and $b h 4$, as well as the activated G-protein, $G_{h t}^{*}$, via the autoreceptors. 


$$
\begin{aligned}
& \frac{d[b h 2]}{d t}=V_{\mathrm{TPH}}\left(t r p, b h 4, G_{h t}^{*}\right)-V_{\mathrm{DRR}}(b h 2, \mathrm{NADPH}, b h 4, \mathrm{NADP}) \\
& \frac{d[b h 4]}{d t}=V_{\mathrm{DRR}}(b h 2, \mathrm{NADPH}, b h 4, \mathrm{NADP})-V_{\mathrm{TPH}}\left(\operatorname{trp}, b h 4, G_{h t}^{*}\right) \\
& \frac{d[\operatorname{trp}]}{d t}=V_{\text {trpin }}(b \operatorname{trp})-V_{\mathrm{TPH}}\left(\operatorname{trp}, b h 4, G_{h t}^{*}\right)-V_{\mathrm{pool}}(\operatorname{trp}, p o o l)-k_{\text {trp }}^{\text {catab }} \cdot \operatorname{trp} \\
& \frac{d[h t p]}{d t}=V_{\mathrm{TPH}}\left(t r p, b h 4, G_{h t}^{*}\right)-V_{\mathrm{AADC}}(h t p) \\
& \frac{d[c h t]}{d t}=V_{\mathrm{AADC}}(h t p)-V_{\mathrm{MAT}}(c h t, v h t)+V_{\mathrm{SERT}}(e h t)-V_{\mathrm{CATAB}}(c h t)-k_{c h t}^{\text {leak }} \cdot c h t \\
& \frac{d[v h t]}{d t}=V_{\text {MAT }}(\text { cht }, v h t)-i n h i b_{h t}\left(G_{h t}^{*}\right) \cdot i n h i b_{h a}\left(G_{h a}^{*}\right) \cdot \text { fire }(t) \cdot v h t \\
& \frac{d[e h t]}{d t}=i n h i b_{h t}\left(G_{h t}^{*}\right) \cdot i n h i b_{h a}\left(G_{h a}^{*}\right) \cdot f \text { fire }(t) \cdot v h t-V_{\mathrm{SERT}}(e h t)-V_{\mathrm{U} 2}(e h t)-k_{\text {eht }}^{\text {rem }} \cdot e h t+k_{\text {ght }}^{\text {leak }} \cdot g h t \\
& k_{\text {cht }}^{\text {leak }} \cdot \operatorname{cht}-k_{5} \cdot e h t \cdot\left(B_{h t}^{\text {tot }}-B_{h t}\right)+k_{6} \cdot B_{h t} \\
& \frac{d[h i a a]}{d t}=V_{\mathrm{CATAB}}(c h t)+V_{\mathrm{CATAB}}(g h t)-k_{\text {hiaa }}^{c a t a b} \cdot h i a \\
& \frac{d[\text { pool }]}{d t}=V_{\text {pool }}(\text { trp }, \text { pool })-k_{\text {pool }}^{c a t a b} \cdot \text { pool } \\
& \frac{d\left[G_{h t}^{*}\right]}{d t}=\beta_{1}\left[k_{1} \cdot B_{h t}^{2} \cdot\left(G_{h t}^{t o t}-G_{h t}^{*}\right)-k_{2} \cdot T_{h t}^{*} G_{h t}^{*}\right] \\
& \frac{d\left[T_{h t}^{*}\right]}{d t}=\beta_{2}\left[k_{3} \cdot\left(G_{h t}^{*}\right)^{2} \cdot\left(T_{h t}^{t o t}-T_{h t}^{*}\right)-k_{4} \cdot T_{h t}^{*}\right] \\
& \frac{d\left[B_{h t}\right]}{d t}=\beta_{3}\left[k_{5} \cdot e h t \cdot\left(B_{h t}^{t o t}-B_{h t}\right)-k_{6} \cdot B_{h t}\right] \\
& \frac{d[g h t]}{d t}=V_{\mathrm{U} 2}(e h t)-V_{\mathrm{CATAB}}(g h t)-k_{g h t}^{l e a k} \cdot g h t \\
& \frac{d\left[G_{h a}^{*}\right]}{d t}=k_{7} \cdot B_{h a}^{2} \cdot\left(G_{h a}^{t o t}-G_{h a}^{*}\right)-k_{8} \cdot T_{h a}^{*} G_{h a}^{*} \\
& \frac{d\left[T_{h a}^{*}\right]}{d t}=k_{9} \cdot\left(G_{h a}^{*}\right)^{2} \cdot\left(T_{h a}^{t o t}-T_{h a}^{*}\right)-k_{10} \cdot T_{h a}^{*} \\
& \frac{d\left[B_{h a}\right]}{d t}=k_{11} \cdot e h a \cdot\left(B_{h t}^{t o t}-B_{h a}\right)-k_{12} \cdot B_{h a}
\end{aligned}
$$

Although btrp and eha are listed as variables, there are no differential equations for them because, in this paper, they are constant or their time courses are specified in the computational experiments. Table 2 gives the parameter choices and references for reactions that have standard Michaelis-Menten kinetics, single substrate, double substrate, or reversible. For reactions with non-standard kinetics, the serotonin autoreceptor, the $\mathrm{H}_{3}$ receptor, and other parts of the model, detailed explanations follow.

Tryptophan hydroxylase (TPH) The kinetics of TPH show substrate inhibition. The Michaelis constants and the substrate inhibition constants are given in Table 3 with references. In [1], the inhibition of TPH by the serotonin autoreceptor was modeled by having the current concentration of eht affect synthesis. However, in this paper we have a kinetic model of the autoreceptor (see below), so TPH is inhibited or excited by whether the concentration of the G-protein, $G_{h t}^{*}$, is above or below its equilibrium value, $G_{\text {hteq }}^{*}$. Little is known about the kinetics of this effect, so we take the slope of this effect to be 2.5 , that is, $\operatorname{inhibsyn}\left(G_{h t}^{*}\right)=1-(2.5)\left(G_{h t}^{*}-G_{h t e q}^{*}\right)$. The full kinetics of TPH are:

$$
V_{\mathrm{TPH}}\left(\operatorname{trp}, b h 4, G_{h t}^{*}\right)=\frac{V_{\max }(\operatorname{trp})(b h 4)}{\left(K_{t r p}+(\operatorname{trp})+\frac{(\operatorname{trp})^{2}}{K_{i}}\right)\left(K_{b h 4}+(b h 4)\right)} \cdot \operatorname{inhibsyn}\left(G_{h t}^{*}\right) .
$$


Table 1 Names of variables

\begin{tabular}{ll}
\hline In equations and text & Full name \\
\hline$b h 2$ & Dihydrobiopterin \\
$b h 4$ & Tetrahydrobiopterin \\
trp & Tryptophan \\
$b t r p$ & Blood tryptophan \\
$h t p$ & 5 -Hydroxytryptamine \\
$c h t$ & Cytosolic serotonin \\
$v h t$ & Vesicular serotonin \\
eht & Extracellular serotonin \\
$h i a a$ & 5-Hydroxyindoleacetic acid \\
pool & The tryptophan pool \\
$G_{h t}^{*}$ & Serotonin activated G-protein \\
$T_{h t}^{*}$ & Serotonin activated T regulatory protein \\
$B_{h t}$ & Serotonin autoreceptors bound to eht \\
$g h t$ & Glial serotonin \\
$G_{h a}^{*}$ & Histamine activated G-protein \\
$T_{h a}^{*}$ & Histamine activated T regulatory protein \\
$B_{h a}$ & Histamine autoreceptors bound to eha \\
$e h a$ & Extracellular histamine \\
\hline
\end{tabular}

Uptake $2\left(V_{\mathrm{UP} 2}\right)$. It is not a new idea that serotonin may be taken up from the extracellular space not only by SERTs but also by other transporters. Shaskan and colleagues suggested this in the 1970s [11] and recently the therapeutic potential for depression of this second uptake has been emphasized by Daws [12] and Horton [13]. The hypothesis is that serotonin can be taken up into glial cells by the dopamine transporter (DAT), the norepinepherine transporter (NET), and the organic cation transporter (OCT) as well as the SERTs. We refer to this uptake into glial cells collectively as Uptake 2 and it is depicted schematically in Fig. 1 . The presence of two uptake mechanisms was confirmed by the in vivo experiments of Hashemi [7], one high affinity but low capacity (SERTs) and one low affinity and high capacity (Uptake 2). In the microdialysis experiments of Bunin and Wightman $[37,40]$ on tissue from the dorsal raphe (DR) and the substantia nigra pars reticulata $(\mathrm{SNr})$, large quantities of serotonin were released into the extracellular space and the concentration of serotonin in the effluent was measured over time. The almost linear decline of serotonin over short times allowed them to estimate the $V_{\max }$ of the uptake and the later decline allowed them to estimate the $K_{m}$. The $K_{m}$ in both regions was $170 \mathrm{nM}$ and the $V_{\max }$ varied from $1800 \mathrm{nM} / \mathrm{s}$ in the DR to $780 \mathrm{nM} / \mathrm{s}$ in the $\mathrm{SNr}$. These values are consistent with fast responses and the fast part of the decline in the hybrid responses measured in vivo by Hashemi [7], so we believe that Bunin and Wightman were, in fact, measuring Uptake 2 and not the SERTs. Thus we take the $K_{m}$ of Uptake 2 to be $.17 \mu \mathrm{M}$. Bunin and Wightman were measuring microdialysis effluent from tissue slices. The Hashemi Lab measures the time dynamics in the extracellular space with microelectrodes in mice in vivo (see below). We expect that the $V_{\max }$ will vary enormously depending on how many glial cells are near the electrode. So we take our minmal baseline value to be $V_{\max }=14 \mu \mathrm{M} / \mathrm{hr}$ but expect that the $V_{\max }$ will be much higher in some circumstances.

The hybrid responses ("Two serotonin uptake mechanisms and the effect of histamine" section) show that Uptake 2 only operates above some threshold that is (usually) above the basal level of eht, which in our model is $60 \mathrm{nM}$. This is consistent with the idea that Uptake 2 is low affinity. We accomplish this in the model by multiplying the kinetics of Uptake 2 by a factor $H$ that equals zero below $60.5 \mathrm{nM}$, increases linearly to 1 at $80.5 \mathrm{nM}$ and is 1 above that (the factor 1000 is because eht is measured in $\mathrm{nM})$.

$$
V_{\mathrm{U} 2}(e h t)=H(1000 \cdot e h t) \frac{V_{\max } \cdot(e h t)}{K_{m}+e h t} .
$$

The $5 H T_{1 B}$ autoreceptor As described in the Introduction, the experiments in the Hashemi Lab showed clearly that autoreceptor effects are long-lasting (seconds to minutes) and that they persist even when the eht concentration returns to normal. It is this persistence that drives the eht concentration well below baseline in the majority of stimulation experiments. Almost certainly these delays are because the cellular machinery by which the autoreceptors act takes time to turn on and turn off. In our original model [1], the autoreceptors act instantaneously because the inhibition of release when eht rises depended on the current value of eht. The experimental advances require a more sophisticated model of the action of autoreceptors.

The $5 H T_{1 B}$ autoreceptor is in the family of $\mathrm{G}$ proteincoupled receptors (GPRC) [41], and there is a large literature on the structure and modeling of GPRCs including diverse second messengers, geometrical configuration, and possible dimerization [42-44]. The binding of an eht molecule to the $5 H T_{1 B}$ autoreceptor causes the release of a G-protein subunit that stimulates a signaling cascade that results in inhibition of release and synthesis. Our purpose here is to create a simple model for our autoreceptor dynamics. In our model, $G_{h t}$ represents $G_{\alpha}-G D P$ (the inactive G-protein subunit) and $G_{h t}^{*}$ represents $G_{\alpha}-$ GTP (the signaling G-protein unit). Most G-protein signals are limited by RGS molecules (regulators of G-protein signaling) that stimulate the G-protein subunit to rebind [45]. $T_{h t}$ represents the inactive RGS protein and $T_{h t}^{*}$ represents the active RGS protein. A schematic diagram of this chemistry is in Fig. 1 and the details are in 
Table 2 Kinetic parameters $(\mu M, \mu M / h, / h)$

\begin{tabular}{|c|c|c|c|c|}
\hline Velocity & Parameter & Model value & Literature value & References \\
\hline \multirow[t]{3}{*}{$V_{\text {AADC }}$} & \multicolumn{4}{|c|}{ Aromatic amino acid decarboxylase } \\
\hline & $K_{m}$ & 160 & 160 & [23] \\
\hline & $V_{\max }$ & 400 & & * \\
\hline \multirow[t]{3}{*}{$V_{\text {CATAB }}$} & \multicolumn{4}{|l|}{ Catabolism of serotonin } \\
\hline & $K_{m}$ & 95 & $94-95$ & {$[24,25]$} \\
\hline & $V_{\max }$ & 4000 & & * \\
\hline \multirow[t]{7}{*}{$V_{\text {DRR }}$} & \multicolumn{4}{|c|}{ Dihydropteridine reductase } \\
\hline & $K_{\text {bh2 }}$ & 100 & $4-754$ & {$[26,27]$} \\
\hline & $K_{\mathrm{NADPH}}$ & 75 & $29-770$ & {$[28-30]$} \\
\hline & $V_{\max }^{f}$ & 5000 & & * \\
\hline & $K_{b h 4}$ & 10 & $1.1-17$ & {$[29,31]$} \\
\hline & $K_{\text {NADP }}$ & 75 & $29-770$ & {$[28-30]$} \\
\hline & $V_{\max }^{b}$ & 3 & & * \\
\hline \multirow[t]{3}{*}{$V_{\text {MAT }}$} & \multicolumn{4}{|c|}{ Vesicular monoamine transporter } \\
\hline & $K_{m}$ & .2 & $.123-.253$ & {$[32,33]$} \\
\hline & $V_{\max }$ & 1230 & & * \\
\hline \multirow[t]{3}{*}{$V_{\mathrm{POOL}}$} & \multicolumn{4}{|c|}{ Linear exchange between trp and pool } \\
\hline & $k_{\text {topool }}$ & 9 & & * \\
\hline & $k_{\text {frompool }}$ & 0.6 & & * \\
\hline \multirow[t]{3}{*}{$V_{\text {SERT }}$} & \multicolumn{4}{|l|}{ Serotonin transporter } \\
\hline & $K_{m}$ & .06 & $0.05-1$ & [34] \\
\hline & $V_{\max }$ & 250 & & * \\
\hline \multirow[t]{5}{*}{$V_{\mathrm{TPH}}$} & \multicolumn{4}{|l|}{ Tryptophan hydroxylase } \\
\hline & $K_{t r p}$ & 40 & 40 & {$[35]$} \\
\hline & $K_{\text {bh4 }}$ & 20 & 20 & {$[35]$} \\
\hline & $V_{\max }$ & 278 & & * \\
\hline & $K_{i}$ (substrate inhibition) & 1000 & 970 & {$[35]$} \\
\hline \multirow[t]{3}{*}{$V_{\text {trpin }}$} & \multicolumn{4}{|c|}{ Neutral amino acid transporter } \\
\hline & $K_{m}$ & 330 & 64 & {$[36]$} \\
\hline & $V_{\max }$ & 700 & & * \\
\hline \multicolumn{5}{|l|}{$V_{\mathrm{U} 2}$} \\
\hline & $K_{m}$ & .17 & 0.17 & {$[37,38]$} \\
\hline & $V_{\max }$ & 14 & & {$[37,38]$} \\
\hline \multicolumn{5}{|c|}{ Linear diffusion or catabolism } \\
\hline & $k_{t r p}^{c a t a b}$ & 2 & & * \\
\hline & $k_{c h t}^{\text {leak }}$ & 1 & & * \\
\hline & $k_{\text {ght }}^{\text {leak }}$ & 1 & & * \\
\hline & $k_{\text {hiaa }}^{\text {catab }}$ & 1 & .82 & [39] \\
\hline & $k_{\text {pool }}^{\text {catab }}$ & 1 & & * \\
\hline & $k_{\text {eht }}^{\text {rem }}$ & 40 & & * \\
\hline \multicolumn{5}{|c|}{ The serotonin autoreceptor } \\
\hline & $G_{h t}^{\text {tot }}$ & 10 & & * \\
\hline & $T_{h t}^{\text {tot }}$ & 10 & & * \\
\hline & $B_{h t}^{\text {tot }}$ & 10 & & * \\
\hline & $k_{1}$ & 20 & & * \\
\hline & $k_{2}$ & 200 & & * \\
\hline & $k_{3}$ & 30 & & * \\
\hline & $k_{4}$ & 200 & & * \\
\hline & $k_{5}$ & 36000 & & * \\
\hline
\end{tabular}


Table 2 (continued)

\begin{tabular}{|c|c|c|c|c|}
\hline Velocity & Parameter & Model value & Literature value & References \\
\hline & $k_{6}$ & 20000 & & * \\
\hline & $\beta_{1}$ & 1 & & * \\
\hline & $\beta_{2}$ & 1 & & * \\
\hline & $\beta_{3}$ & 1 & & * \\
\hline \multicolumn{5}{|c|}{ The histamine $\mathrm{H}_{3}$ receptor } \\
\hline & $G_{h a}^{\text {tot }}$ & 1 & & * \\
\hline & $T_{h t}^{\text {tot }}$ & 60 & & * \\
\hline & $B_{h t}^{\text {tot }}$ & 10 & & * \\
\hline & $k_{7}$ & 4.32 & & $*$ \\
\hline & $k_{8}$ & 1.296 & & * \\
\hline & $k_{9}$ & 14.4 & & * \\
\hline & $k_{10}$ & 25.92 & & * \\
\hline & $k_{11}$ & 432 & & * \\
\hline & $k_{12}$ & 1440 & & * \\
\hline \multicolumn{5}{|c|}{ Other constants (varied in some experiments) } \\
\hline & NADP & 26 & & * \\
\hline & $\mathrm{NADPH}$ & 330 & & * \\
\hline & btrp & 96 & & * \\
\hline & eha & 1.39 & & * \\
\hline
\end{tabular}

*See text

Table 3 The steady state

\begin{tabular}{|c|c|c|c|}
\hline Variable & Concentration $(\mu \mathrm{M})$ & Velocity & $\begin{array}{l}\text { Rate }(\mu \\
M / h)\end{array}$ \\
\hline$b h 2$ & 0.1 & $V_{\text {trpin }}$ & 157.8 \\
\hline$b h 4$ & 0.9 & $V_{\mathrm{TPH}}$ & 3.99 \\
\hline $\operatorname{trp}$ & 20.2 & $V_{\text {AADC }}$ & 3.99 \\
\hline btrp & 96 & $V_{\text {CATAB }}$ & 1.58 \\
\hline htp & 1.61 & $V_{\text {MAT }}$ & 127.4 \\
\hline cht & 0.04 & Release & 127.4 \\
\hline vht & 67.5 & $V_{\text {SERT }}$ & 125.1 \\
\hline eht & 0.060 & Removal & 2.4 \\
\hline hiaa & 1.59 & $V_{U 2}$ & 0.0 \\
\hline pool & 113 & & \\
\hline$G_{h t}^{*}$ & 0.86 & & \\
\hline$T_{h t}^{*}$ & 1.01 & & \\
\hline$B_{h t}$ & 0.97 & & \\
\hline$g h t$ & 0.0 & & \\
\hline$G_{h a}^{*}$ & 0.69 & & \\
\hline$T_{h a}^{*}$ & 12.69 & & \\
\hline$B_{h a}$ & 2.94 & & \\
\hline eha & 1.39 & & \\
\hline
\end{tabular}

the differential equations for $G_{h t}^{*}, T_{h t}^{*}$ and $B_{h t}$. The bound eht stimulates the conversion of $G_{h t}$ to its active form $G_{h t}^{*}$, and $G_{h t}^{*}$ stimulates the conversion of $T_{h t}$ to its active form, $T_{h t}^{*}$. In turn, $T_{h t}^{*}$ stimulates the deactivation of $G_{h t}^{*}$.
We assume that total autoreceptors, total $\mathrm{G}$ protein, and total RGS protein are constants.

It has been understood since the $1970 \mathrm{~s}$ that the $5 H T_{1 B}$ autoreceptors sense eht. When eht goes up, they inhibit both the synthesis of serotonin and the release of serotonin from the vesicles and when eht goes down they facilitate synthesis and release [46-51]. Thus $e h t$ provides a kind of end-point feedback for the entire serotonergic system from tryptophan in the plasma to eht in the extracellular space. Unfortunately, relatively little is known about the amplitude of these effects or the ranges over which they operate. Furthermore, these kinetics likely vary from varicosity to varicosity and cell to cell depending on the expression level of the $5 H T_{1 B}$ autoreceptors. We take relatively simple formulas for the effect of $G_{h t}^{*}$ on release and synthesis:

$$
\begin{aligned}
& \operatorname{inhib}\left(G_{h t}^{*}\right)=1.89-(s)\left(G_{h t}^{*}-G_{h t e q}^{*}\right), \\
& \operatorname{inhibsyn}\left(G_{h t}^{*}\right)=1-(s)\left(G_{h t}^{*}-G_{h t e q}^{*}\right),
\end{aligned}
$$

where $G_{\text {hteq }}^{*}$ is the equilibrium value of the activated G-protein and $s$ is the slope of the effect, higher $s$, stronger effect. Our normal values for $s$ are $s=12.5$ for the inhibition of release and $s=2.5$ for inhibition of synthesis. As we will see below, the experiments in the Hashemi Lab give some information on the strength $s$ of the autoreceptor effect. It is also known [52] that the autoreceptors modulate reuptake, but this effect is not 
included in the model. Finally, we remark that serotonin is known to be an appetite suppressant [53], and therefore the concentration in the extracellular space should be at least somewhat sensitive to meals.

The histamine $\mathrm{H}_{3}$ receptor. We've taken the model for the $H_{3}$ receptor from our paper [54]. The schematic diagram is in Fig. 1 and the differential equations for $B_{h a}$, $G_{h a}^{*}$, and $T_{h a}^{*}$ are given above and the values of the parameters are in Table 2. $G_{h a}^{*}$ inhibits the release of serotonin by multiplying release by the function inhib $_{h a}\left(G_{h t}^{*}\right)=1-(5)\left(G_{h a}^{*}-G_{\text {haeq }}^{*}\right)$, where $G_{\text {haeq }}^{*}$ is the equilibrium value of the activated G-protein. Note that, at equilibrium, this multiplier is $=1$.

Serotonin binding protein and release In our model there is a constant basal rate of serotonin release at steady state. In the experiments on mice in the Hashemi $\mathrm{Lab}$, the medial forebrain bundle (MFB) is stimulated for $2 \mathrm{~s}$. The antidromic spikes propagate back to stimulate the serotonin neurons in the dorsal raphe nucleus (DR) which in turn send spikes to projection regions in which extra serotonin is released. The FSCV probe in the projection region (see below) measures the concentration of serotonin in the extracellular space over $30 \mathrm{~s}$. The question is how should we model the release of serotonin over the $30 \mathrm{~s}$ period-the first term in the differential equation for eht? The question is complicated by the existence of serotonin binding protein (SBP) that is attached to the inner wall of vesicles and binds serotonin tightly $[55,56]$. We assume that the dissociation is a first order reaction

$$
S B P-\text { serotonin } \stackrel{b}{\longrightarrow} S B P+\text { serotonin } .
$$

If we start with one unit (nM) of SBP-serotonin being dumped into the extracellular space at time zero, then $S B P(t)=e^{-b t}$ and $\operatorname{serotonin}(t)=1-e^{-b t}$. The rate of release of serotonin is the derivative, $b e^{-b t}$. However, we are stimulating for two seconds, so SBP-serotonin complexes are continuously dumped into the extracellular space between $t=0$ and $t=2 \mathrm{~s}$. Assume that the rate of dumping is $1 \mathrm{nM} / \mathrm{s}$, so in $2 \mathrm{~s}, 2 \mathrm{nM}$ of the complex are dumped. What is the rate of appearance, $R(t)$, of serotonin for $t \leq 2$ and $t>2$ ?

$$
R(t)=\int_{0}^{t} \chi_{[s, 2]} b e^{-b(t-s)} d s \text { for } t \leq 2,
$$

and

$$
R(t)=\int_{0}^{2} \chi_{[s, 2]} b e^{-b(t-s)} d s \text { for } t>2 .
$$

Here $\chi_{[s, 2]}$ is the function that is 1 on the interval $[s, 2]$ and zero otherwise. A straightforward calculation shows that:

$$
R(t)= \begin{cases}1-e^{-b t} & \text { if } t \leq 2, \\ e^{-b(t-2)}-e^{-b t} & \text { if } t>2 .\end{cases}
$$

Thus, for a $2 \mathrm{~s}$ stimulation, as was the case for the data used below, the rate of release will be proportional to fire $(t)=$ basal rate $+r \cdot R(t)$ where $r$ is the strength of the stimulation. Unfortunately, the dissociation constant $b$ (inverse seconds) is not known, but we think it is in the range $0.5 \leq b \leq 2$ from our simulations of the Hashemi data, so we'll take $b=1$ as our baseline case. The release of serotonin into the extracellular space will also be proportional to $v h t$ and it will also depend on the inhibition from the serotonin autoreceptors and the histamine $\mathrm{H}_{3}$ receptor. Thus, overall release as a function of time will be

$$
\operatorname{inhib}_{h t}\left(G_{h t}^{*}\right) \cdot \operatorname{inhib}_{h a}\left(G_{h a}^{*}\right) \cdot \text { fire }(t) \cdot v h t,
$$

which is the first term in the differential equation for $e h t$ above.

Minor changes Since we have added a glial cell compartment, serotonin is catabolized in the neuron and in the glial cell, and not in the extracellular space (as in the 2010 model). We have added leakage of serotonin from the cytosol to the extracellular space [57], indicated by the dashed lines in Fig. 1. Because most of $v h t$ is bound to serotonin binding protein, we have reduced the linear back diffusion from the vesicles to the cytosol from 40 to 1 (contained in the formula for $V_{\mathrm{MAT}}$ ). The linear removal of eht from the extracellular space represents diffusion out of the tissue and uptake by the circulatory system.

A systems population model All individuals, whether mouse or human, are different, and the variation is important for understanding experimental results and for precision medicine. We investigate this biological variation by creating a population model of the deterministic model given above. It is known that the expression levels of most enzymes can vary by about $25 \%$ or more between individuals [14-16]. Therefore, to create a systems population model, we choose new $V_{\max }$ values for each (or a subset) of the enzymes and transporters in Fig. 1 by selecting independently from a uniform distribution between $75 \%$ and $125 \%$ of the normal value. In some cases we choose larger variation ("Using population models to understand drug efficacy and clinical measurements" section). We then run the model to steady state and record all the concentrations and velocities. That is one virtual person (or mouse). If we do this 1000 times, we obtain a database of virtual individuals that we can analyze using the usual statistical tools. The difference is that all of these individuals have the same set of differential equations; only the coefficients are different. So we can experiment with the model to find the mechanistic reasons for particular statistical phenomena (as we will 
do below). And, we can sometimes verify the results of our populations models by comparing to known databases (for example, see the systems population model for one-carbon metabolism in [58]).

Caveats Every mathematical model model is an oversimplified representation of complicated and variable physiology. In this model we chose $K_{m}$ values for enzymes and transporters from the literature but chose $V_{\max }$ values so the model would reproduce steady state values consistent with the literature. In any case, $V_{\max }$ values depend on enzyme expression levels that vary in time and differ widely from person to person [14-16]. We have included a glial cell in the model to represent all the non-neuronal cells that can take up and catabolize serotonin. Good measurements of the size of the vesicular compartment and the size of the extracellular space (per varicosity) are not available and so we treat those compartments as though they are the same size. We have referred to the "concentration" of autoreceptors and bound autoreceptors but we have no good way of estimating effective concentrations for the autoreceptors that are on the varicosity surface, so the units are arbitrary.

Using the model to make predictions In the Background, we explained that one should expect as much as $25 \%$ variation in many of the parameters of the model because of biological variation in individual cells or because one is studying different brain regions. Thus our "standard" model with the parameters from Table 2 should be regarded as a model for an "average" mouse in an average brain region. We expect large individual variation in individual mice and, indeed, that is what one sees in the data and in our systems population model (Fig. 6a, b). Given this variation, what does it mean to claim that we have constructed a "good" model. Certainly, it does not mean that our standard deterministic model with a fixed set of parameters is "right" and explains everything. We believe that: (1) A good model should contain the major players that biologists would say are involved in the phenomena we are studying, and the model should be constructed using as much as possible experimental information on concentrations and kinetics; (2) One should be able to test hypothesis by running simulations of the model; (3) The model should be useful to provide a theoretical framework to help experimentalists interpret data.

We use the model in several different ways. Often we determine the parameter changes that are necessary so that the model curves or model data points fit the experimental ones (as in Results 3.4 and 3.5). These parameter changes (such as the strength of Uptake 2 or the strength of the $5 H T_{1 B}$ autoreceptors or the rapidity and duration of the autoreceptor response) are then predictions that could be verified experimentally. Sometimes we conduct theoretical experiments and don't fit data as in "The effect of meals" section where we ask how much variation in eht should one expect from the daily variation in tryptophan input due to meals. Even in such cases, the theoretical results are predictions that could be verified experimentally. Finally, sometimes we ask interesting theoretical questions of the model such as how much variation in model parameters is necessary to obtain the variation seen in the data ("The steady state" and "Variability in response to stimulation" sections). Experimental validation or invalidation of model predictions will suggest improvements to the model and better theoretical understanding. Indeed, this new model was necessary because of the inability of the older model [1] to explain the long-lasting autoreceptor effect seen in experimental data ("The dynamics of the autoreceptors" and "Two serotonin uptake mechanisms and the effect of histamine" sections). Thus, we don't expect "the model" to be fixed, but to evolve in response to new experiments.

Fast scan cyclic voltammetry To make carbon fiber microelectrodes (CFM) for fast scan cyclic voltammetry (FSCV), a $7 \mu \mathrm{m}$ carbon fiber (Goodfellow Corporation, PA, USA) was aspirated through a borosilicate glass capillary $(0.6 \mathrm{~mm}$ external diameter, $0.4 \mathrm{~mm}$ internal diameter, AM systems, Inc., Sequim, WA). This capillary was pulled to a fine tip via a micropipette puller (Narishige Group, Tokyo, Japan) to form a seal around the carbon. Silver conducting epoxy paint was used to make electrical connection between the carbon fiber and hardware connections. The exposed carbon fiber was cut to $150 \mu \mathrm{m}$ and Nafion was electropolymerized onto the electrode surface for improved selectivity [59 original MS]. To make FSCV measurements, the CFM was directly implanted into the brain region of interest (coordinates given below). The serotonin-selective potential waveform, the Jackson waveform described in detail elsewhere [59] (0.1 - 1.0 to $-0.2-1.0 \mathrm{~V}$ at $1000 \mathrm{Vs}-1)$ was applied to the carbon at $10 \mathrm{~Hz}$. In the time between waveform application, the potential was held at the resting potential of $0.1 \mathrm{~V}$ to minimize interfering species and to preconcentrate the analyte of interest and increase sensitivity. At discrete potentials, the analyte of interest becomes oxidized (on the anodic scan) and reduced (on the cathodic scan). Oxidation and reduction events generate Faradaic currents, which can be observed by subtracting out the large, capacitative background current. As a result, FSCV is used for measuring evoked changes in nanomolar but cannot measure absolute concentrations. Data from FSCV is analyzed via cyclic voltammograms (CVs), which is the plot of current as a function of potential applied, and current vs. time (iT) curves. The former provides qualitative information about the identity of the species while the latter provides quantitative information about 
release and reuptake of the analyte in question via comparison of the signal to calibration curves constructed with standard concentrations.

Animals and surgical procedures All protocols described herein are in accordance with the Guide for the Care and Use of Laboratory Animals at the University of South Carolina, and have been approved by the Institutional Animal Care and Use Committee (IACUC) at this Institution, which operates with accreditation from the Association for Assessment and Accreditation of Laboratory Animal Care (AAALAC)." Anesthesia is induced via intraperitoneal injections of urethane (25\% dissolved in $0.9 \% \mathrm{NaCl}$ solution, Hospira, Lake Forest, IL, USA). Once the animals were fully anesthetized as assessed with lack of toe pinch reflex, they were secured into a stereotaxic instrument (David Kopf Instruments, Tujunga, CA, USA) and surgery was performed to implant the electrodes into appropriate coordinates:

Posterior Hypothalamus: (CFM: AP -2.45, ML: +0.50, DV: -5.45 to -5.55 w.r.t. Bregma; stimulating electrode: AP: -1.07 , ML: +1.10 , DV: -5.00 w.r.t Bregma).

Hippocampus: (CFM: AP -2.91, ML: +3.35, DV: -2.5 to -3.0 w.r.t. Bregma; stimulating electrode: AP: -1.58 , ML: +1.0 , DV: -4.8 to -5.0 w.r.t. Bregma).

Substantia nigra pars reticulata: (CFM: AP: -3.28 , ML: +1.4, DV: -4.2 to -4.8 w.r.t. Bregma; stimulating electrode: AP: -1.58 . ML: +1.0 , DV: -4.8 to -5.0 w.r.t. Bregma).

A pseudo- $\mathrm{Ag} / \mathrm{AgCl}$ electrode was placed in the contralateral hemisphere to complete the circuit and act as a reference electrode. A heating pad was used to maintain body temperature around $37^{\circ} \mathrm{C}$ throughout the procedures and experiments (Braintree Scientific, Braintree, MA, USA). We reported in prior work that a power analysis recommended a minimum $\mathrm{n}$ size of 3.5 (rounded to 4) and maintained that there, along with a strict animal exclusion criteria (i.e. animals that did not survive the experiment, animals in which the electrodes broke and animals in which the identity of the analyte could not be confirmed electrochemically via inspection of cyclic voltammograms [60].

Numerical computations The differential equations in Table 1 were solved using the ODE15s in MatLab. The parameters were as indicated in Table 2, except as indicated explicitly in the discussion and figures about each simulation experiment. The MatLab code is available from the authors.

\section{Results and discussion}

\section{The steady state}

Table 3 shows the concentrations of the variables at the normal steady state of the model and also shows many of the velocities. Concentrations are in $\mu \mathrm{M}$ except for eht which is in $\mathrm{nM}$, and velocities are in $\mu \mathrm{M} / \mathrm{h}$. A major change from our 2010 model is that the steady state eht concentration is now $60 \mathrm{nM}$ instead of $0.7 \mathrm{nM}$. The Hashemi Lab has repeatedly verified that the extracellular serotonin concentration in mice is in the range 40-80 nM [60-62], although it varies considerably between the different regions to which the dorsal raphe and medial raphe project. The steady state concentration of histamine in the extracellular space is taken from [54]. We are assuming that the cutoff for Uptake 2 (see "Methods" section) is normally at $60.5 \mathrm{nM}$, which is why there is no serotonin in the glia at the normal steady state. Uptake 2 comes into play during the stimulation experiments (below) when serotonin release is stimulated.

The concentration of btrp is $96 \mu \mathrm{M}$ as found by [36]. Note that only a small fraction of the trp imported from the blood goes to the synthesis of serotonin, the rest being catabolized or taken to pool that represents all of the other uses of trp in the cell. The synthesis pathway is quite slow compared to release, reuptake via the SERTs, and packaging into vesicles by MAT. At the normal steady state, approximately $98 \%$ of the released serotonin is returned to the cytosol by the SERTs; the other $2 \%$ (removal) diffuses out of the tissue or is taken up by blood vessels. The steady state concentration for hiaa is consistent with the range found in [63].

The steady state shown for eht $(60 \mathrm{nM})$ is for an "average" mouse (or an "average" person), but, of course, each individual is different and will have different parameters, a different steady state, and different responses to stimulation as we will see below. The natural variation in enzyme expression levels between individuals is approximately $25 \%,[14,64,65]$. Our systems population model (see Methods) allows us to see how the variation affects the distribution of eht levels in the population. We allowed the $V_{\max }$ values of TRPin, TPH, AADC, MAT, MAO, Uptake 2, and SERT to vary by $25 \%$ above and below their normal values independently. In addition we allowed fire $(t)$ to vary $25 \%$ above and below its normal value and the slope of the function $\operatorname{inh} i b\left(G_{h t}^{*}\right)$ to vary by $25 \%$. We are particularly interested in the effect of the $5 H T_{1 B}$ autoreceptors, so we computed the eht distribution in three cases: standard autoreceptors, high autoreceptors (twice as strong as standard), and no autoreceptors. For standard autoreceptors, the distribution of eht is given by the green bars in Fig. 2b. The distribution is broad with a range of 45 to $70 \mathrm{nM}$, a mean of $58.7 \mathrm{nM}$ and a standard deviation of $4.3 \mathrm{nM}$. This distribution is similar to the distributions seen in the pre-frontal cortex of mice in the Hashemi Lab [60]. For no autoreceptors, the distribution is given by the pink bars in Fig. 2a. It is much broader, with a range of 30 to $90 \mathrm{nM}$, a mean of $58.2 \mathrm{nM}$ and standard deviation of $11.1 \mathrm{nM}$. For high 
autoreceptors, the resulting quite narrow distribution of eht values is shown by the blue bars in Panel A. The distribution has a range of 50 to $67 \mathrm{nM}$, a mean of 59.2 $\mathrm{nM}$, and a standard deviation of $2.7 \mathrm{nM}$. This shows the effect of the $5 H T_{1 B}$ autoreceptors on the distribution of eht. Using data on the distribution of eht values, we can compute the likely value of the slopes, s, of the functions inhib and inhibsyn, which is how we arrived at our "normal" values of 12.5 and 2.5 , that is, we can estimate the strength of the autoreceptor effect. Note that all the distributions fall much more rapidly to the right of the peak than to the left. This is because Uptake 2 operates above the normal steady state and transports eht into the glia. It is likely that Uptake 2 is an evolutionary mechanism to prevent serotonin syndrome $[66,67]$.

Each time that we run the systems population model, we get slightly different distributions of eht. The distributions shown in Fig. 2 are typical examples of the three cases: standard autoreceptors, high autoreceptors, and no autoreceptors. The systems population model demonstrates the strong effect of the autoreceptors on the distribution of eht values in variable populations.

\section{The effect of tryptophan input}

Many studies have shown that low brain serotonin is associated with depression [68-75], so there has been great interest in investigating whether and how brain serotonin can be affected by diet. For several reasons, it is not easy to estimate how changes in dietary tryptophan affect eht. Tryptophan, the amino acid precursor to serotonin, competes for the L-transporter at the blood-brain barrier with the other neutral amino acids [76-78], and since the L-transporter is normally operating at close to saturation the amount of blood tryptophan transported depends on the concentrations of other amino acids. Furthermore, much tryptophan in the blood is bound to albumin [79] and Fernstrom has shown that because of this binding the amount of tryptophan transported depends on the order of protein and carbohydrate consumption [80]. Finally, tryptophan hydroxylase, TPH, shows substrate inhibition, so if cytosolic tryptophan rises, the synthesis rate can go up or down depending on the concentration of tryptophan.

Nevertheless, we can use the model to see how vesicular serotonin, $v h t$, and extracellular serotonin, eht, change as plasma tryptophan (btrp) changes. Figure 3a shows that both vht (blue curve) and eht change substantially if the autoreceptor effect is turned off. Panel b shows that, when the autoreceptor effect is turned on vht changes dramatically but eht varies much less than in Panel a. This is because when eht is below normal, the autoreceptors increase release, which depletes $v h t$ and the opposite occurs when eht is above normal. The magnitude of the change of $v h t$ is consistent with experiments in the Hashemi Lab [81] where serotonin cells were incubated in media with $40 \mu \mathrm{M}$ tryptophan and $140 \mu \mathrm{M}$ tryptophan, respectively. On electrical stimulation, the high tryptophan cells released approximately twice as much eht as the low tryptophan cells. Since release is proportional to $v h t$, this difference is what would be predicted by the model results in Fig. 3b.

We can also examine the effect of low tryptophan by using the systems population model. The slope of the $5 H T_{1 B}$ autoreceptor was varied by $25 \%$ around its
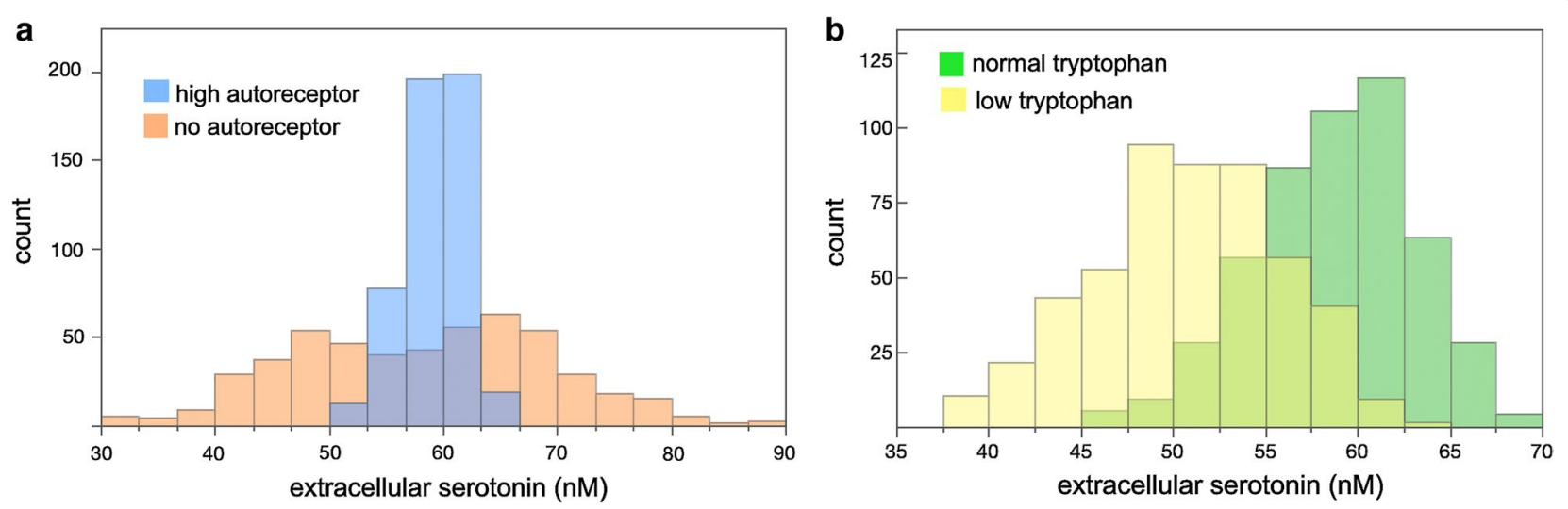

Fig. 2 Autoreceptors effect the distribution of eht values in the systems population model. In our systems population model we varied the strength of fire $(t)$ and the $V_{\text {max }}$ values of Trypin, TPH, AADC, MAT, MAO, Uptake 2, and SERT by $25 \%$. a Shows the distribution of eht if there is no autoreceptor effect (pink bars) or if the autoreceptor effect is twice as strong as normal (blue bars). The green bars in $\mathbf{b}$ show the distribution of eht if the autoreceptor effect is "normal" (12.5 for the slope of inhib and 2.5 for the slope of inhibsyn). The green bars are similar to distributions measured in the Hashemi Lab (data not shown). The yellow bars show the distribution of eht if blood tryptophan is lowered from its normal value of $96 \mu \mathrm{M}$ to $50 \mu \mathrm{M}$. The distribution of eht moves substantially lower 

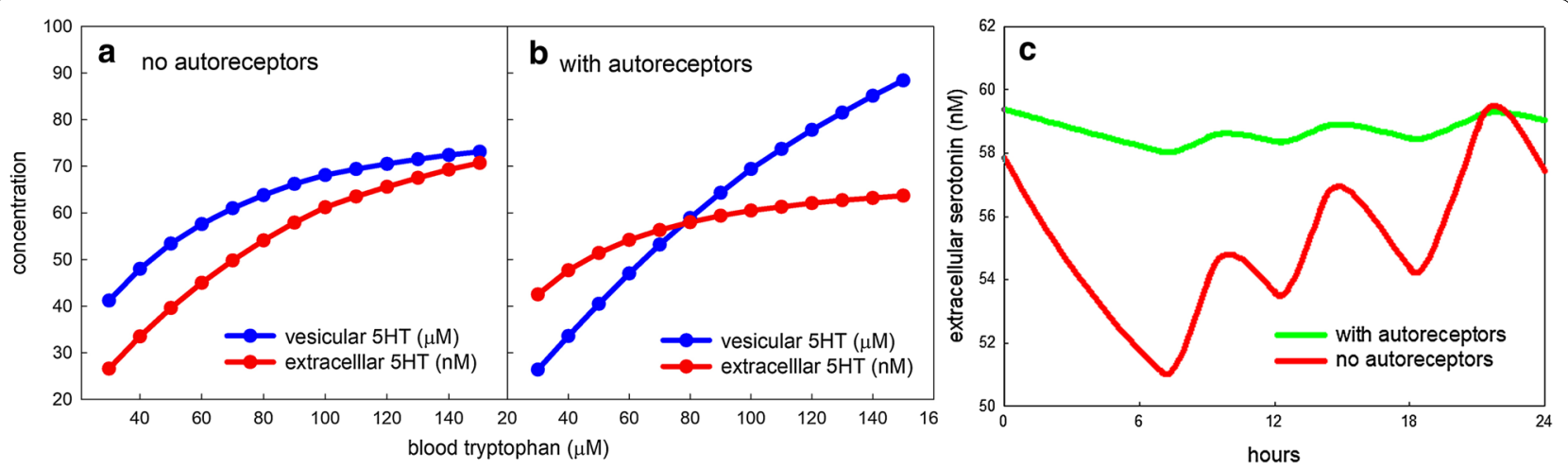

Fig. 3 The effect of tryptophan input. a Shows the steady state values of vesicular serotonin, vht (blue curve), and extracellular serotonin, eht (red curve), over a range of values of blood tryptophan ( $96 \mu \mathrm{M}$ being normal) if the autoreceptors are turned off. $\mathbf{b}$ Shows the analogous curves if the autoreceptor effect is normal. The vht curve varies much more and the eht curve varies much less (for explanation, see the text). c Shows the effect of three daily meals on the extracellular concentration of eht with no autoreceptor effect (red curve) and normal autoreceptors (green curve). The autoreceptors greatly dampen the fluctuations of eht due to meals

standard value of $s=12.5$, and similarly the 7 enzymes and fire $(t)$ were varied by $25 \%$ as discussed in the caption to Fig. 2. The green bars in Fig. 2 show the distribution of eht if blood tryptophan is held constant at its normal value of $96 \mu \mathrm{M}$, while the yellow bars show the distribution of eht if blood tryptophan is held constant at $50 \mu \mathrm{M}$. As can be clearly seen, lowering blood tryptophan moves the eht distribution substantially to the left.

\section{The effect of meals}

During a $24 \mathrm{~h}$ period, the plasma amino acid concentration can vary by as much as a factor of 6 but more typically varies by a factor of 2 to $4[36,82,83]$ because of meals. This means that $v h t$ and eht are never really at steady state but vary during the day and we can calculate the effect of this variation on the serotonin system. As we will see, this gives a good demonstration of the homeostatic effect of the autoreceptors and Uptake 2. To simulate meals, we assume that the normal concentration of blood tryptophan is doubled for two hours after breakfast and lunch, and for $3 \mathrm{~h}$ after dinner, and is correspondingly lower at other times so that the average concentration is $96 \mu \mathrm{M}$ as we assume at steady state. In our model, it is the activated $G$-coupled protein, $G_{h t}^{*}$, that inhibits release by multiplying the rate of release by the factor:

$$
\operatorname{inhib}\left(G_{h t}^{*}\right)=1-(s)\left(G_{h t}^{*}-G_{h t e q}^{*}\right) .
$$

where $s=12.5$, normally. If $s=0$, there is no autoreceptor effect because $e h t$ and $G_{h t}^{*}$ don't affect release. If $s=12.5$, the normal value, the autoreceptors inhibit release when eht is above its normal value (and therefore $G_{h t}^{*}$ is above its normal value). And, when eht is below its normal value, $\operatorname{inh} i b\left(G_{h t}^{*}\right)$ is above its normal value so release (per action potential) is increased. The dynamic changes in eht due to meals are shown in Fig. 3c for no autoreceptors (red curve) and normal autoreceptors (green curve). When there is no autoreceptor effect, eht oscillates between (approximately) $51 \mathrm{nM}$ and $60 \mathrm{nM}$ during the day. With the normal autoreceptor effect, the oscillations of eht go from approximately $58 \mathrm{nM}$ to $60 \mathrm{nM}$. The average eht in both cases is well below the steady state value of $60 \mathrm{nM}$. This is because upward deviations of btrp do not have much effect on eht, but downward deviations have a large effect (see Fig. 3b). The reason is that Uptake 2 is quite strong above $60 \mathrm{nM}$ and it limits the upward deviations of eht when btrp goes up. This is the same reason that the distribution of normal eht steady states in the population model (the green bars in Fig. 2b) has a long tail to the left but falls off sharply to the right of $60 \mathrm{nM}$.

\section{The dynamics of the autoreceptors}

In the previous sections we illustrated the effects of the $5 H T_{1 B}$ autoreceptors on steady state values of eht or long term responses to external variation such as meals. Now, we turn our attention to using the model to understand and interpret data from the Hashemi Lab on the time course of serotonin in the extracellular space after serotonin release has been stimulated. The Hashemi lab uses Fast Scan Cyclic Voltammetry (FSCV) to measure the time course of eht in vivo in different brain regions (see "Methods" section). In this section we examine data recently collected in vivo of responses of male and female mice in the CA2 region of the hippocampus [62]. The medial forebrain bundle was stimulated and the antidromic spikes stimulate the DRN that projects to the hippocampus and releases serotonin into the extracellular space. The serotonin is taken up by the SERTs and Uptake 2 . The mean curves of $e h t$ for 23 male mice and 23 female 
mice are given by the red dots in Fig. 4a, b. By varying a small number of parameters, we were able to obtain model response curves (blue) that are very similar to the responses in the experimental data. The model curves are given by the corresponding blue curves. The male and female average curves are quite similar although the female curve dips further below baseline. The model parameters that were varied are given in Table 4 and discussed below.

It is worthwhile to discuss how the shapes of the curves are influenced by the autoreceptor dynamics. Figure $4 \mathrm{c}$ shows the time course of the three variables, $B_{h t}, G_{h t}^{*}, T_{h t}^{*}$. The red curve is $B_{h t}$, which is eht bound to the $5 H T_{1 B}$ autoreceptors, and it mimics the eht curve as it should. The blue curve, which is the activated G-protein, $G_{h t}^{*}$, rises more slowly and peaks later than the $B_{h t}$ curve. The black curve, which is the activated regulator of G-protein signaling, $T_{h t}^{*}$, rises even more slowly and peaks even later. Notice than when eht has returned to baseline (at about 12-14 s), $G_{h t}^{*}$ is still above its baseline and therefore it is still inhibiting release; this is what drives the eht curve below baseline. Still later, the increase in $T_{h t}^{*}$ drives $G_{h t}^{*}$ down below its baseline so serotonin is being released faster than normal; this causes the eht curve to turn upwards towards baseline. Finally, all three variables, $B_{h t}, G_{h t}^{*}, T_{h t}^{*}$, relax towards their respective baselines. The parameters $\beta_{1}, \beta_{2}$, and $\beta_{3}$ multiply the right hand sides of the differential equations for $G_{h t}^{*}, T_{h t}^{*}$, and $B_{h t}$ and speed up or slow down the differential equations depending on whether they are greater than 1 or lower than 1 . In the standard model they are all set to 1 . These parameters change the shapes of the $G_{h t}^{*}$ and $T_{h t}^{*}$ curves and therefore the eht curve also. As one can see in Table 4, they are somewhat different for the male and female average curves. The higher female values cause the female average curve to dip further below baseline than the average male curve. Figure 6a shows 17 males response curves, and one can see how different their shapes are, probably because the different animals have different autoreceptor dynamics.

We determined the value of the $V_{\max }$ of Uptake 2 in the normal model by requiring that the distribution of values of eht in the systems population model be similar to experimental distributions (see Fig. 2) measured in the hippocampus. But we expect that in some nuclei and some experiments the $V_{\max }$ of Uptake 2 will be much larger depending on the density of glial cells, the prevalence of OCT, DA, and NET transporters and the proximity of the measuring electrode to the glial cells. We needed the high values here to bring down the model curve from the peak rapidly as is seen in the experimental data. Uptake 2 is zero below the lower number of the $\mathrm{H}$ range and equals one above the upper number

\begin{tabular}{|c|c|c|c|}
\hline Parameter & Meaning & Male & Female \\
\hline$V_{\max }$ of $V_{\mathrm{U} 2}$ & Strength of Uptake 2 & 1680 & 1680 \\
\hline Uptake 2 & $\mathrm{H}=0$ below and 1 above & $60.5-75.5$ & $60.5-70.5$ \\
\hline slope of inhib & strength of $5 H T_{1 B}$ & 10 & 12.5 \\
\hline$\beta_{1}$ & Scale for $G_{h t}^{*}$ dynamics & 0.8 & 0.85 \\
\hline$\beta_{2}$ & Scale for $T_{h t}^{*}$ dynamics & 0.6 & 0.7 \\
\hline$\beta_{3}$ & Scale for $B_{h t}$ dynamics & 0.8 & 0.85 \\
\hline r & Strength of fire( $t)$ & 18 & 18.5 \\
\hline
\end{tabular}
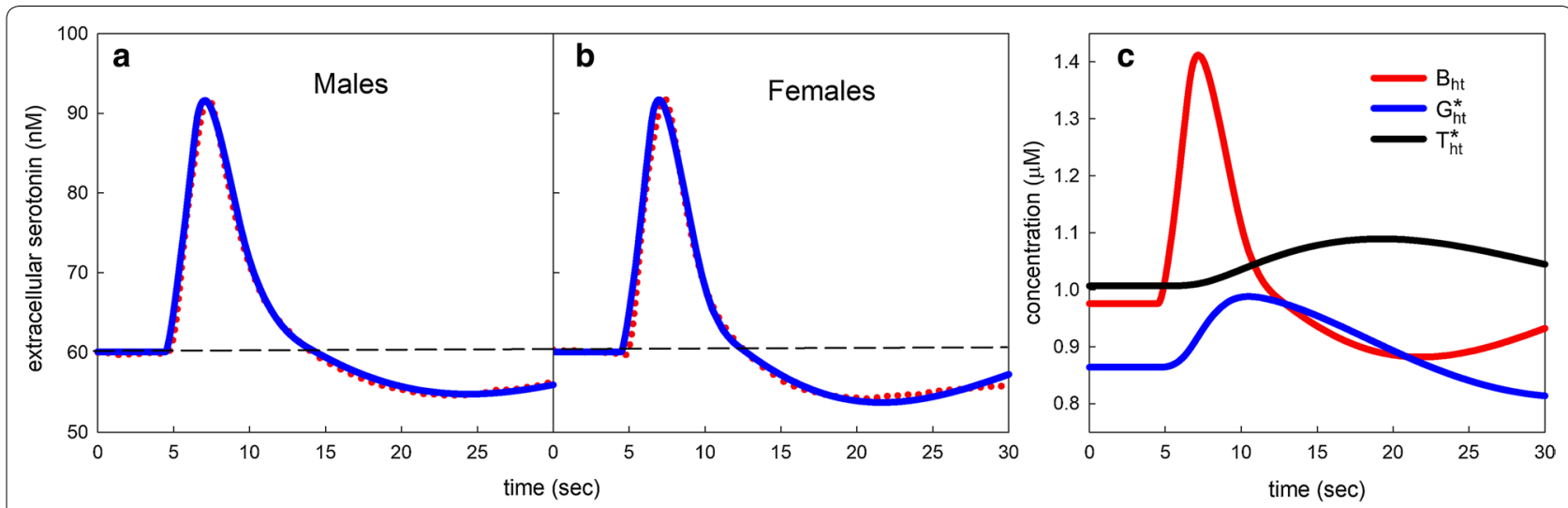

Fig. 4 Male and female responses and autoreceptor dynamics. The red dots in $\mathbf{a}$, $\mathbf{b}$ show the experimental averages of $(n=23)$ male and $(n=23)$ female responses of extracellular serotonin, eht. The blue curves show the model simulations. Parameters for the simulations are given in Table 4 and discussed below. The dashed horizontal line is the average baseline concentration of eht in the CA2 region of the hippocampus. The male and female average responses are similar. c Shows the dynamics of the three variables, $B_{h t}, G_{h t}^{*}, T_{h t}^{*}$ of the serotonin $5 H T_{1 B}$ autoreceptor dynamics. "See the Discussion in the text". The experimental data is replotted from [62] 
and increases linearly in between. The slope of $i n h i b_{h t}$ represents how sensitive the inhibition of release is to the concentration of $G_{h t}^{*}$. So the female autoreceptors not only respond more quickly but inhibit release more strongly (see Table 4). The parameter $r$ is proportional to how much serotonin is released after stimulation of the MFB. All other parameters were as in the standard normal model described in the Methods. It is not surprising that the average response curves are different for males and females and that the best fit parameters are different because estradiol affects both TPH expression and a variety of 5HT receptors [84-86].

\section{Two serotonin uptake mechanisms and the effect of histamine}

In 2014 we published experimental and mathematical results that altered our view of serotonin clearance after stimulation in two major ways [7]. In the experiments, the medial forebrain bundle (MFB) was stimulated. The antidromic spikes stimulated the DRN and the serotonin concentration was measured in vivo in the substantia nigra pars reticulata $(\mathrm{SNr})$ of mice. The first major observation was that the serotonin concentration first went up, but then descended below baseline in almost all experiments (see Figs. 4a, b, 5a, b). As discussed in "The dynamics of the autoreceptors" section, this showed that the effect of the $5 H T_{1 B}$ autoreceptors is long-lasting ( $30 \mathrm{~s}$ to $1 \mathrm{~min}$ ) because they still inhibit release after the eht concentration has returned to normal and this drives the eht concentration below baseline. In our 2010 model [1], the autoreceptor effect was instantaneous in that eht inhibited release when it was above baseline and stimulated release when it was below. The new experimental evidence showed that this was wrong and led directly to the new $5 H T_{1 B}$ autoreceptor model in this paper.

The second major finding in [7] was that there were clearly two different uptake mechanisms at work. Consider the experimental curves (red dots) in the three panels of Fig. 5; each curve is the average of 5 animals. The slope of the eht curve is the rate of uptake and one can see that there are two distinct slopes. In some measurements (Fig. 5a), the eht curve descended rapidly to baseline; we call these responses "fast." In some measurements (Fig. 5c), the eht curve descended slowly and linearly to baseline; we call these responses "slow." And, in some experiments (Fig. 5b), the eht curve descended rapidly for a while but then switched to descending slowly; we call these responses "hybrid." The majority of experimental responses were hybrid. As explained in the Methods, we hypothesized that the "fast" uptake transports serotonin into glial cells via the dopamine transporter (DAT), the norepinepherine transporter (NET), and the organic cation transporter (OCT). This is what we call Uptake 2, and the fact that most response curves were "hybrid" suggested that Uptake 2 normally operates only above a concentration that is higher than the steady state level of eht. We assume that the "slow" uptake is via SERTs.

In [7], we used a very simple mathematical model to help explain the data. It had a single differential equation for $e h t$ with two uptakes and a release term multiplied by a function of time $1-A(t)$ where $A(t)$ represented the "strength" of the autoreceptor effect as a function of time. We found that if we chose $A(t)$ appropriately, we could match different fast. slow, and hybrid responses. Thus, there was no internal chemistry of the serotonin neuron

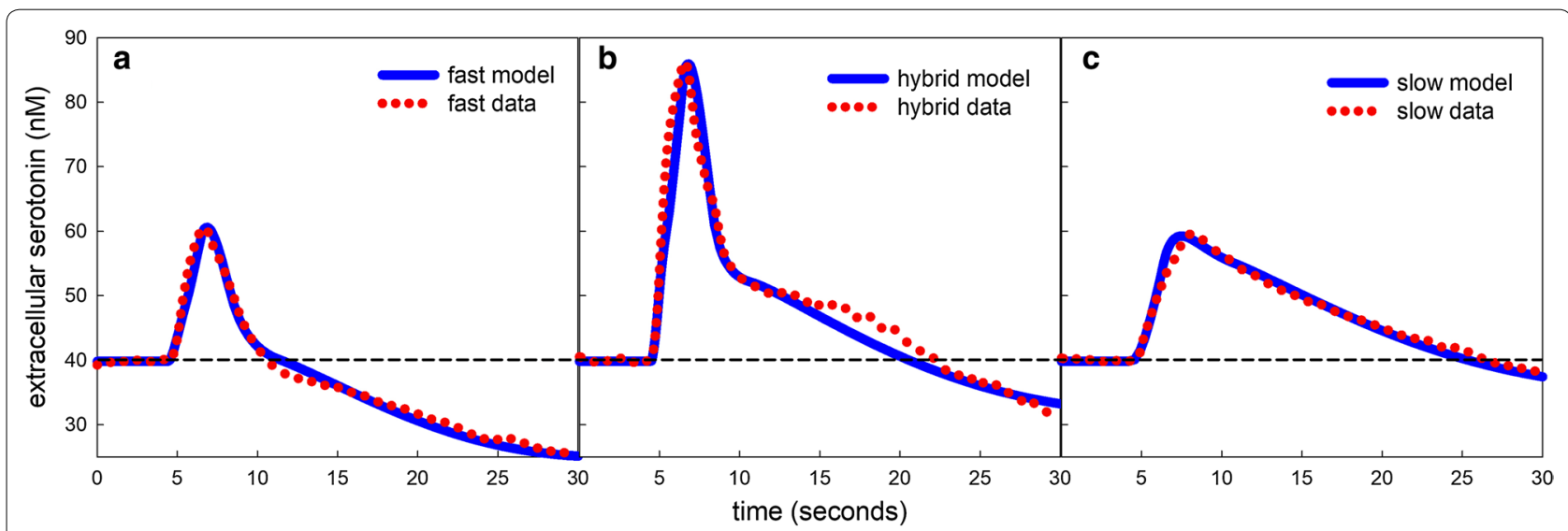

Fig. 5 Fast, hybrid, and slow responses in the SNr. a, c Show simulations of fast and slow responses with experimental data taken from [7]. b Shows a simulation and previously unpublished data for a hybrid response. Red dots indicate experimental data and blue curves are model simulations. All responses were in the SNr. The dashed horizontal line is the average baseline concentration of eht in the SNr. Parameters for the simulations are shown in Table 5 and the significance of the parameters is discussed in the text 

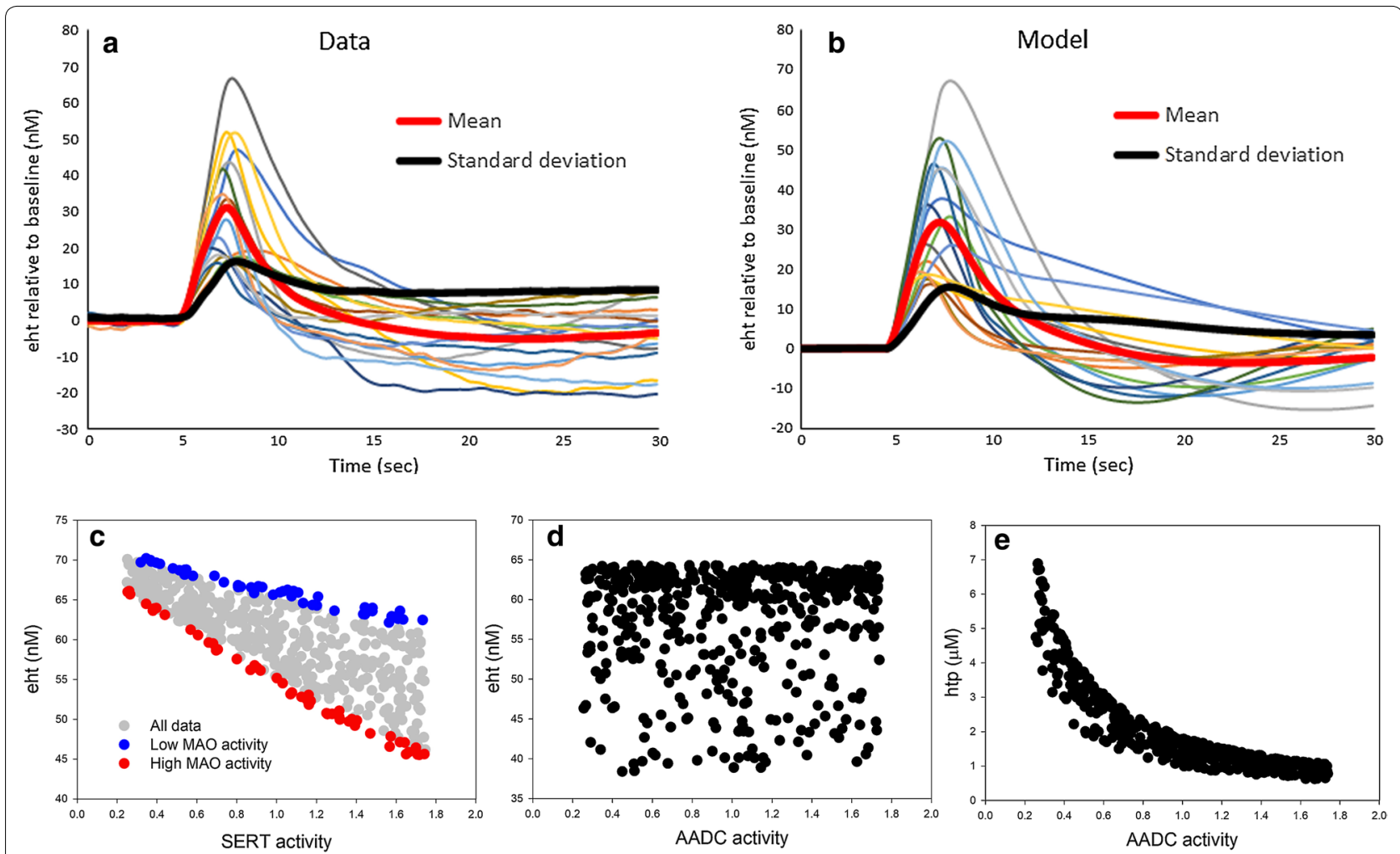

Fig. 6 Investigations using the systems population model. a Shows the time courses of eht in the hippocampus of 17 male mice after $2 \mathrm{~s}$ of stimulation at $t=5 \mathrm{~s}$ (Hashemi Lab). The thick red and black curves are the time courses of the mean and standard deviation, respectively. The response curve are diverse and have different heights, peaks and shapes. b Shows 17 randomly selected response curves in a systems population model of 1000 individuals with 40\% independent variation in many parameters in the model (see text in "Variability in response to stimulation" section for details). The red and black curves are the time courses of the mean and the standard deviation of the 1000 model individuals, respectively. c Shows a systems population model of 500 individuals where the expression values of SERT and MAO were varied from 25 to $175 \%$ of normal and all other constants were fixed. The blue dots are individuals with low MAO activity and the red dots are individuals with high MAO activity. SSRIs have a greater effect on individuals with high MAO activity. $\mathbf{d}$, e The results from a systems population model (500 individuals) where blood tryptophan and the expression level of AADC were varied from 25 to 175\% of normal and all other constants were fixed. d Shows that eht is uncorrelated to AADC activity. e Shows that as AADC activity goes down htp concentration goes up so the flux through AADC remains nearly constant. This may explain why supplementation by vitamin B6 (a co-factor for AADC) is an ineffective treatment for depression

and the autoreceptor effect was put in by hand. Our purpose here is to show that our new full serotonin model with its complicated autoreceptor dynamics could also match the varied responses, fast, slow, hybrid in the SNr. However, when we ran the model the eht curves would go below baseline and then curve up towards baseline (like the male and female average curves in Fig. 4 or the male experimental curves in Fig. 6a), because once $T^{*}$ drives $G^{*}$ below baseline extra serotonin is released. But the experimental curves in the $\mathrm{SNr}$ (Fig. 5) do not curve up, which was a clear indication that something else was going on.

In [87], it was shown that when the MFB is stimulated, then not only is serotonin released in the $\mathrm{SNr}$, but histamine is also released. Furthermore, there was early experimental evidence that histamine can inhibit serotonin release [88, 89] and this was confirmed by our study [8] in 2016. Finally, in 2017 we published a full mathematical model of a histamine neuron and that model included the dynamics of the $\mathrm{H}_{3}$ autoreceptor for histamine [54]. It is known [89] that $H_{3}$ autoereceptors do occur on serotonin varicosities in the $\mathrm{SNr}$, so we included an $H_{3}$ receptor for histamine on our serotonin varicosity (see Fig. 1 and "Methods" section). We do not have the time course of histamine in the $\mathrm{SNr}$ because in 2014 the measurement techniques were not yet developed. So we will take our histamine time course in the extracellular space, eha, from the control and model curves in Fig. 5 of [54]. Note how complicated the dynamics of eht are. When one stimulates the MFB, serotonin is released into the extracellular space stimulating dynamical changes in the $5 H T_{1 B}$ autoreceptor variables, $B_{h t}, G_{h t}^{*}, T_{h t}^{*}$. However, 
histamine also increases in the extracellular space stimulating dynamical changes in the $\mathrm{H}_{3}$ receptor variables, $B_{h a}, G_{h a}^{*}, T_{h a}^{*}$. Both of the activated G-proteins, $G_{h t}^{*}$ and $G_{h a}^{*}$ inhibit serotonin release via the functions $\operatorname{inhib}\left(G_{h t}^{*}\right)$ and $i n h i b_{h a}\left(G_{h t}^{*}\right)$, respectively; see the differential equation for $e h t$.

Surprisingly, it was quite easy to give adjustments for a small number of parameters (Table 5) that distinguish between fast, slow, and hybrid responses. First, we raised the $V_{\max }$ of SERT from 250 to 433 and this lowered the steady-state value of eht from $60 \mathrm{nM}$ to $39.8 \mathrm{nM}$ consistent with the measurements in [60]. Note that the slope of the slow parts of the experimental curves (red dots) in Fig. $5 \mathrm{a}-\mathrm{c}$ are very similar, so it is not surprising that the $V_{\text {max }}$ of 433 for SERT worked in all three cases (Table 5).

We discuss each of the other relevant parameters in turn. The $V_{\max }$ of Uptake 2 indicates its strength. It is quite consistent for repeated measurements of one animal but varies widely between animals almost certainly because it depends on the geometry of electrode placement relative to serotonin varicosities and glial cells. Uptake 2 is zero below the lower number of the $\mathrm{H}$ range and equals one above the upper number and increases linearly in between. The size of this $V_{\max }$ is determined by the rapidly decreasing portion of the curve after the peak for Fig. 5a, b. Uptake 2 has little effect on the slow response in Panel c because the curve peaks at $59 \mathrm{nM}$ and Uptake 2 does start affecting uptake until the concentration is above $55 \mathrm{nM}$. The appropriate Uptake 2 transition range is determined roughly by the transition from fast decrease to slow decrease.

The slopes of three inhib functions represent how sensitive the inhibition of release or synthesis is to the concentrations of $e h t$ and $e h a$, respectively. To fit this data we had to greatly weaken the sensitivity of the two serotonin functions, inhib and inhibsyn, and the strength of the inhibition of serotonin release by the $\mathrm{H}_{3}$ receptors varied in the three cases as indicated in Table 5. The parameter $r$ is proportional to how much serotonin is released by the stimulation. In our modeling we've found that $r$ is consistent with repeated measurements on one animal but varies widely between animals. This is not surprising since electrode placement differs between animals as does the stimulation of the MFB. All other parameters in the model were as in the normal standard model described in the Methods.

The modeling shows that the main differences between fast, slow, and hybrid depend on the transition region for the function $H$ that governs the concentration range where Uptake 2 becomes functional. It is particularly gratifying that Threlfell et al. [89] found that not only does histamine play a major role in regulating serotonin in the $\mathrm{SNr}$, but they also found that there are very few
Table 5 Parameter values for fast, hybrid, and slow

\begin{tabular}{lllll}
\hline Parameter & Meaning & Fast & Hybrid & Slow \\
\hline$V_{\text {max }}$ of $V_{\text {SERT }}$ & Strength SERT & 433 & 433 & 433 \\
$V_{\text {max }}$ of $V_{\text {U2 }}$ & Strength of Uptake 2 & 3220 & 5600 & 1400 \\
Uptake 2 & $\mathrm{H}=$ 0 below and 1 & $40-50$ & $52-62$ & $55-65$ \\
& above & & & \\
Slope of inhib & Strength of 5HT $1 B$ & $(.2)(12.5)$ & $(.1)(12.5)$ & $(.1)(12.5)$ \\
Slope of inhibsyn & Strength of $5 H T_{1 B}$ & $(.2)(12.5)$ & $(.1)(2.5)$ & $(.1)(2.5)$ \\
Slope of inhib & Strength of $H_{3}$ & 5 & 3 & 2 \\
$r$ & Strength of fire $(t)$ & 10.3 & 22 & 4.5 \\
\hline
\end{tabular}

$5 H T_{1 B}$ autoreceptors on serotonin varicosities in the $\mathrm{SNr}$, which corresponds exactly to what we found by modeling (the (.1) and (.2) multipliers for the slopes of $i n h i b_{h t}$ and inhib $\left.{ }_{\text {htsyn }}\right)$.

We note that the response curves in Fig. 5 look quite different from the response curves in Fig. 4 where the $5 \mathrm{HT}$ concentration drops below baseline and then bends back toward baseline within $25 \mathrm{~s}$ after stimulation. There are two reasons for the difference. First, the measurements are in two different brain nuclei, the CA2 region of the hippocampus in Fig. 4 and the SNr in Fig. 5. We expect that the response curves after stimulation will be quite different in different regions because SERT and autoreceptor densities vary between regions and the speed of the autoreceptor effect will vary depending on G-protein concentrations. The second, and probably more important reason, is that when the MFB is stimulated $\mathrm{HA}$ as well as $5 \mathrm{HT}$ is released into the $\mathrm{SNr}$ and $\mathrm{HA}$ binds to $\mathrm{H}_{3}$ receptors on $5 \mathrm{HT}$ terminals and inhibits 5HT release. The time course of that inhibition depends on the dynamics of the G-proteins associated to the $H_{3}$ receptor, and it is that HA inhibition that causes the response curves in Fig. 5 to keep descending during the first $25 \mathrm{~s}$ after stimulation.

\section{Variability in response to stimulation}

In "The dynamics of the autoreceptors" section, we used the deterministic model to fit the mean eht response curves for male and female mice in the hippocampus. We showed that small changes of parameters allowed us to fit both mean curves in response to $2 \mathrm{~s}$ of stimulation at $t=5 \mathrm{~s}$. In this section, we confront the variability in the male curves themselves. Figure 6a shows the responses of the 17 male mice. The experimental responses are measured and graphed for each mouse relative to the baseline level of $e h t$ that is represented in Panel a by $e h t=0$. One can see how large the variation is. The curves peak at different times and at different heights. Most, but not all, of the curves descend below baseline and their shapes are quite different; some continue descending while others 
reach a minimum and then rebound towards zero. The thick red curve is the mean and the thick black curve is the standard deviation, which is substantial even between 15 and $30 \mathrm{~s}$.

We investigated what variation in the main parameters of the model would be necessary to obtain the variation seen in the experiments. To do this we created a virtual population of 1000 individuals with the independent variations in parameters. The following parameters were varied uniformly from 40 below to $40 \%$ above their normal values: the $V_{\max }$ values for $V_{\mathrm{AADC}}, V_{\mathrm{CATAB}}, V_{\mathrm{MAT}}$, $V_{\mathrm{SERT}}, V_{\mathrm{TPH}}, V_{\mathrm{U} 2}$; the slope of inhib and inhibsyn; eha, the concentration of histamine in the extracellular space, and $\beta$ that controls the speed of the autoreceptors. In addition, we varied the the parameter $r$ in fire $(t)$ by $25 \%$ and the time of the peak by $20 \%$.

Figure $6 \mathrm{~b}$ shows a random sample of 17 of the 1000 model male curves. The thick red curve is the mean of the 1000 model curves and the thick black curve is the standard deviation. The mean curve matches the experimental mean curve very well. The model standard deviation curve is very close to the experimental standard deviation except that at long times (20 to $30 \mathrm{~s}$ ) it descends slightly while the experimental standard deviation remains constant. Overall, one can see visually that the 17 model curves and the 17 experimental curves look similar as groups of curves. For each of the 1000 individuals, we record their steady state values as well as the values of all of their parameters so we can use multi-linear regression to find which parameters contributed most to the variation in the response curves. At $t=7 \mathrm{~s}$ (roughly the time of the peak), the three variables that contributed most, in order, were the strength of fire(t), the timing of the peak in fire $(\mathrm{t})$, and the $V_{\max }$ of the SERTs. At $t=15 \mathrm{~s}$ (when most of the curves have returned to near baseline), the three parameters that contributed most to the variation in response were the $V_{\max }$ of TPH, the speed of the autoreceptors, and the $V_{\max }$ of MAT.

The purpose of autoreceptors is to stabilize the concentration of eht in the extracellular space. Thus, one would expect that if the autoreceptors were stronger (larger $s$ ) then one would need larger variation in parameters to obtain the variation in the experimental curves, and conversely, if the autoreceptors were weaker, then less variation in parameters would be needed to obtain the experimental variation. Indeed, this is true (simulations not shown).

\section{Using population models to understand drug efficacy and clinical measurements}

It is known that the expression levels of most enzymes can vary by about $25 \%$ or more between individuals [1416]. This means that the $V_{\max }$ values of all the enzymes and transporters in our model vary by at least $25 \%$ and that any population of individuals will express this diversity. This poses large issues for drug discovery and treatment because it means that different individuals will react very differently to drugs, as is well-known [90-92]. In "Variability in response to stimulation" section, we used our systems population model to investigate how much variation in many variables of the model is necessary to obtain the observed variation in experimental response curves. In this section, we give two brief, simple examples that show how to use variation in a small number of variables to investigate questions about drug efficacy and clinical measurements.

It is well known that most antidepressants have limited therapeutic benefits for many patients [93, 94], and it is therefore important to find what patient characteristics lead to greater efficacy. In Fig. 6c, we show results from our systems population model where we varied only two constants, the expression level $\left(V_{\max }\right)$ of SERT and the expression level of MAO, from 25 to $175 \%$ of normal. Each dot is an individual in a population of 500 . The $y$-axis is the concentration of eht, extracellular serotonin, and the $\mathrm{x}$-axis is the expression level of SERT. The blue dots are the individuals with low MAO activity and the red dots are individuals with high MAO activity. The conclusion is clear. Blocking SERTs with an SSRI (equivalent to lowering the expression level) will have a much greater effect on individuals with high MAO activity than on individuals with low MAO activity. Therefore, the systems population model suggests that it is high MAO individuals that will benefit the most from an SSRI.

Next, aromatic amino acid decarboxylase (AADC) is a key enzyme on the synthesis pathway of serotonin and AADC requires vitamin $B 6$ as a cofactor. This raises the question of whether vitamin B6 status could be correlated with depression. In fact, correlations have been found [95-97] and vitamin B6 supplementation has been suggested for depression. However, the clinical results have been disappointing [98]. Why? To investigate this question, we varied blood tryptophan and the $V_{\max }$ of AADC from 25 to $175 \%$ in our systems population model. We already showed in "The effect of tryptophan input" section that eht depends in increasing fashion on blood tryptophan, so we concentrate on AADC here. Figure $6 \mathrm{~d}$ shows that eht is completely uncorrelated with AADC activity and panel e shows why. As AADC activity goes down, its substrate, $h t p$, builds up and this compensates for the reduction in expression level of AADC because the normal concentration level of $h t p$ is way below the $K_{m}$ of AADC (see Table 2). Thus, deficiency or excess of the vitamin $\mathrm{B} 6$ co-factor does not change the flux, $V_{\mathrm{AADC}}$, very much. This explains why supplementary vitamin B6 has not been a successful treatment for depression. 


\section{Conclusions}

We have created a new model of serotonin metabolism including transport of tryptophan from the blood, synthesis of serotonin, packaging into vesicles, release, reuptake and control by autoreceptors. We have shown that the models can be used to investigate the distribution of values of serotonin in the extracellular space and the effects of tryptophan input and meals. We have demonstrated how the models can be used to understand the behavior of response curves in the extracellular space in different brain nuclei. We used the systems population model to investigate the origins of the variation in response curves in different animals, and we showed how the systems population model can be used in drug discovery and to understand clinical measurements. The codes for both the deterministic model and the systems population model are available from the authors and can be used by other researchers to investigate the serotonergic system.

\section{Acknowledgements}

The authors are grateful for federal support and for the support of their universities for their continuing collaboration.

\section{Authors' contributions}

All the authors participated in the formulation of the project and the development of the ideas. An early version of the code was written by FS-M and later versions by WD, HFN, and MCR. Experiments were carried out by $\mathrm{PH}$. Experiments with the model were carried out by JB, WD, HFN and MR. The manuscript was written by MR and proofread by all the authors.

\section{Funding}

Partial support for this research came from NIH through 1R01MH10656301A1(PH, JB, MR, HFN) and 1R21MH109959-01A1(PH, JB, MR, HFN) and the NSF through support for the Mathematical Biosciences Institute DMS-0931642 (JB, FS-M). The funding bodies had no influence on the study design, or the analysis of the experiments, or the writing of computer code, or the writing of the manuscript.

\section{Availability of data and materials}

Experimental data is available from the Hashemi Lab at the University of South Carolina. Codes for the deterministic model and the systems population model are available from HFN and MR at Duke University.

\section{Ethics approval and consent to participate}

All protocols were in accordance with the Guide for the Care and Use of Laboratory Animals and have been approved by the Institutional Animal Care and Use Committee (IACUC) at the University of South Carolina.

\section{Consent for publication}

Not applicable.

\section{Competing interests}

The authors declare that they have no competing interests.

\begin{abstract}
Author details
${ }^{1}$ Department of Mathematics, The Ohio State University, 231 W 18th Ave., Columbus, OH 43210, USA. ${ }^{2}$ Department of Mathematics, Duke University, Durham, NC 27708, USA. ${ }^{3}$ qPharmetra, LLC, Denver, CO 80203, USA. ${ }^{4}$ Department of Bioengineering, Imperial College, London SW7 2AZ, UK. ${ }^{5}$ Department of Biology, Duke University, Durham, NC 27708, USA.
\end{abstract}

Received: 3 June 2020 Accepted: 29 August 2020

Published online: 23 September 2020
References

1. Best JA, Nijhout HF, Reed MC. Serotonin synthesis, release and reuptake in terminals: a mathematical model. Theor Biol Med Model. 2010;7:34

2. Best JA, Nijhout HF, Reed MC. Models of dopaminergic and serotonergic signaling. Pharmacopsychiatry. 2010;43(Supp. 1):561-6.

3. Best J, Oakley G, Reed M, Nijhout HF. Mathematical Models: Interactions between serotonin and dopamine in Parkinson's disease. In: Rana AQ, editor. Etiology and Pathophysiology of Parkinson's Disease. London: Tech; 2011.

4. Best J, Reed M, Nijhout HF. Bursts and the efficacy of selective serotonin reuptake inhibitors. Pharmacopsychiatry (to appear); 2011.

5. Reed M, Nijhout HF, Best J. Mathematical insights into the effects of levodopa. Front Integrative Neurosci. 2012;6:1-24.

6. Reed M, Nijhout HF, Best J. Computational studies of the role of serotonin in the basal ganglia. Front Integrative Neurosci. 2013;7:1-8.

7. Wood KM, Zeqja A, Nijhout HF, Reed MC, Best JA, Hashemi P. Voltammetric and mathematical evidence for dual transport mediation of serotonin clearance in vivo. J Neurochem. 2014;130:351-9.

8. Samaranayake S, Abdalla A, Robke R, Nijhout HF, Reed M, Best J, Hashemi P. A voltammetric and mathematical analysis of histaminergic modulation of serotonin in the mouse hypothalamus. J Neurochem. 2016;138:374-83.

9. West A, Best J, Abdalla A, Nijhout HF, Reed M, Hashemi P. Voltammetric evidence for discrete serotonin circuits, linked to specific reuptake domains, in the mouse medial prefrontal cortex. Neurochem Inter. 2019:123:50-8.

10. Samaranayake $S$, Abdalla A, Robke R, Wood K, Zeqja A, Hashemi P. In vivo histamine voltammetry in the mouse premammillary nucleus. Analyst. 2015;140:3759-65.

11. Shaskan E, Snyder S. Kinetics of serotonin accumulation into slices from rat brain: relationship to catecholamine uptake. J Pharmacol Exp Ther. 1970;175:404-18.

12. Daws L, KoekWN. Mitchell: Revisiting serotonin reuptake inhibitors and the therapeutic potential of "uptake-2" in psychiatric disorders. ACS Chem Neurosci. 2013;4:16-21.

13. Horton R, Apple E, Owens W. Decynium-22 enhances ssri-induced antidepressant-like effects in mice: uncovering novel targets to treat depression. J Neurosci. 2013;33:10534-43.

14. Oleksiak M, Churchgill G, Crawford D. Variation in gene expression within and among natural populations. Nat Genetics. 2002;32:261-6.

15. Boeuf S, Keijer J, Hal N, Klaus S. Individual variation of adipose gene expression and identification of covariated genes by cdna microarrays. Physiol Genomics. 2002:11:31-6.

16. Sigal A, Milo R, Chen A, Gava-Zatorsky N, Klein Y, Liron Y, Rosenfeld N, Danon T, Perzov N, Alon U. Variability and memory of protein levels in human cells. Nat Lett. 2006;444:643-6.

17. Zill P, Buttner A, Eisenmenger W, Meuller $\mathrm{H}-J$, Ackenheil M, Bondy B. Analysis of tryptophan hydroxylase $\mathrm{i}$ and ii mrna expression in the human brain: A post-mortem study. J Psychol Res. 2004;41:168-73.

18. Kish S, Furukawa Y, Chang L-J, Tong J, Ginovart N, Wilson A, Houle S, Meyer J. Regional distribution of serotonin transporter protein in postmortem human brain is the cerebellum a sert-free brain region? Nucl Med Biol. 2005;32:123-8

19. Gonzalez A, Walther D, Pazos A, Uhl G. Synaptic vesicular monoamine transporter expression: distribution and pharmacologic profile. Mol Brain Res. 1994:22:219-26.

20. Varnas K, Hall H, Bonaventure P, Sedvall G. Autoradiographic mapping of 5-ht $1 \mathrm{~b}$ and 5-ht $1 \mathrm{~d}$ receptors in the post mortem human brain using [3h] gr 125743. Brain Res. 2001;915:47-57.

21. Lanfumey L, Hamon M. Central 5-ht1a receptors: regional distribution and functional characteristics. Nucl Med Biol. 2008;27:429-35.

22. Saura J, Kettler R, Prada MD, Richards J. Quantitative enzyme radioautography with 3h-ro 41-i 049 and 3h-ro 19-6327 in vitro: Localization and abundance of mao-a and mao-b in rat cns, peripheral organs, and human brain. J Neurosci. 1992;12:1977-99.

23. Sumi $C$, Ichinose $H$, Nagatsu T. Characterization of recombinant human aromatic l-amino acid decarboxylase expressed in cos cells. J Neurochem. 1990;55:1075-8.

24. Fowler CJ, Ross SB. Selective inhibitors of monoamine oxidase a and b: biochemical, pharmacological, and clinical properties. Med Res Rev. 1984;4(3):323-58. 
25. Gottowik J, Cesura AM, Malherbe P, Lang G, Prada MD. Characterisation of wild-type and mutant forms of human monoamine oxidase $a$ and $b$ expressed in a mammalian cell line. Fed Eur Biochem Soc. 1993;317(1-2):152-6.

26. Armarego WL, Ohnishi A, Taguchi H. New pteridine substrates for dihydropteridine reductase and horseradish peroxidase. Biochem J. 1986;234:335-42.

27. Bailey SW, Ayling JE. 6,6-dimethylpterins: stable quinoid dihydropterin substrate for dihydropteridine reductase and tetrahydropterin cofactor for phenylalanine hydroxylase. Biochem. 1983;22:1790-8.

28. Firgaira FA, Cotton RG, Jennings I, Danks DM. Use of naphthoquinone adsorbant for the isolation of human dihydropteridine reductase. Methods Enzymol. 1987;142:116-26.

29. Firgaira FA, Cotton RG, Danks DM. Isolation and characterization of dihydropteridine reductase from human liver. Biochem J. 1981;97:31-43.

30. Schomburg D, Schomburg I. 6,7-dihydropteridine reductase. Springer Handbook Enzymes. 2005;23:248-72.

31. Craine JE, Hall ES, Kaufman S. The isolation and characterization of dihydropteridine reductase from sheep liver. J Biol Chem. 1972;247:6082-91.

32. Slotkin TA, Seidler FJ, Whitmore WL, Lau C, Salvaggio M, Kirksey DK. Rat brain synaptic vesicles: uptake specificities of [3h]norepinephrine and [3h]serotonin in preparations from whole brain and brain regions. $J$ Neurochem. 1978;31:961-8.

33. Rau KS, Birdsall E, Volz TJ, Riordan JA, Adair AJBI, Bitter R, Gibb JW, Hanson GR, Fleckenstein AE. Methamphetamine administration reduces hippocampal vesicular monoamine transporter-2 uptake. J Pharmacol Exp Ther. 2006:318:676-82.

34. Feldman RS, Meyer JS, Quenzer LF. Principles of Neuropharmacology. Sunderland: Sinauer Associates Inc; 1997

35. McKinney J, Knappskog PM, Haavik J. Different properties of the central and peripheral forms of human tryptophan hydroxylase. J Neurochem. 2005;92:311-20

36. Kilberg MS, Haussinger D. Mammalian amino acid transport, mechanisms and control. New York: Plenum Pr; 1992.

37. Bunin M, Prioleau C, Mailman R, Wightman R. Release and uptake rates of 5-hydroxytryptamine in the dorsal raphe and substantia nigra of the rat brain. J Neurochem. 1998;70:1077-87.

38. Daws L, Montenez S, Owens W, Gould G, Frazer A, Toney G, Gerhardt G. Transport mechanisms governing serotonin clearance in vivo revealed by high speed chronoamperometry. J Neurosci Methods. 2005;143:49-62.

39. Echizen $H$, Freed CR. Measurement of serotonin turnover rate in rat dorsal raphe nucleus by in vivo electrochemistry. J Neurchem. 1984:42:1483-6.

40. Bunin M, Wightman M. Quantitative evaluation of 5-hydroxytryptamine (serotonin)neuronal release and uptake: An investigation of extrasynaptic transmission. J Neurosci. 1998;18:4854-60.

41. Koenig J. Signal reception: G protein-coupled receptors. In: Davies R, Morris B, editors. Molecular Biology of the Neuron. Oxford: Oxford University Press; 2006.

42. Filzola M. Advances in Experimental medicine and Biology. G ProteinCoupled Receptors - Modeling and Simulation. Dordrecht: Springer; 2014

43. Strasser A, Wittmann H-J. Modelling of GPCRs: A Pratical Handbook. New York: Springer; 2013.

44. Herrick-Davis K. Functional significance of serotonin receptor dimerization. Exp Brain Res. 2013;230:375-86.

45. Willars G. Mammalian rgs proteins: multifunctional regulators of cellular signalling. Sem Cell Develop Biol. 2006;17:363-76.

46. Starke K, Gothert M, Kilbinger H. Modulation of neurotransmitter release by presynaptic autoreceptors. Physiol Rev. 1989;69:864-989.

47. Gothert M. Presynaptic serotonin receptors in the central nervous system. Ann NY Acad Sci. 1990;604:102-12.

48. Estaban S, Llado J, Sastre-cool A, Garcia-Sevilla JA. Activation and desensitization by cyclic antidepressant drugs of $\alpha 2$-autoreceptors, $\alpha$ 2-heteroreceptors and 5-ht1a-autoreceptors regulating monoamine synthesis in the rat brain in vivo. Naunyn-Schmiedeberg's Arch Pharmacol. 1999:360:135-43.

49. Roth BL, Lopez E, Patel S, Kroeze WK. The multiplicity of serotonin receptors: uselessly diverse molecules or an embarrassment of riches? Neuroscientist. 2000;6:252-62.
50. Adell A, Celada P, Abella MT, Artigasa F. Origin and functional role of the extracellular serotonin in the midbrain raphe nuclei. Brain Res Rev. 2002:39:154-80.

51. Hjorth S, Suchowski CS, Galloway MP. Evidence for 5-ht autoreceptormediated, nerve impulse-independent, control of 5-ht synthesis in the rat brain. Synapse. 1995;19:170-6.

52. Daws L, Gerhardt G, Frazier A. 5-ht1b antagonists modulate clearance of extracellular serotonin in rat hippocampus. Neurosci Lett. 1999;266:165-8.

53. Noach E. Appetite regulation by serotonergic mechanisms and effects of d-fenfluramine. Netherlands J Med. 1994;45:123-33.

54. Best J, Nijhout HF, Samaranayake S, Hashemi P, Reed M. A mathematical model for histmine synthesis, release, and control in varicosities. Theor Biol Med Model. 2017;14:24.

55. Gershon M, Liu K, Karpiak S, Tamir H. Storage of serotonin in vivo as a complex with serotonin binding protein in central and peripheral serotonergic neurons. J Neurosci. 1983;3:1901-11.

56. Liu K-P, Gershon M, Tamir H. Identification, purification, and characterization of two forms of serotonin binding protein from rat brain. J Neurochem. 1985:44:1289-301.

57. Hilber B, Scholze P, Doroskar M, Sandtner W, Holy M, Boehm S, Singer E, Sitte H. Serotonin-transporter mediated efflux: A pharmacological analysis of amphetamines and non-amphetamines. Neuropharmacology. 2005;49:811-9.

58. Duncan T, Reed M, Nijhout HF. A population model of folate-mediated one-carbon metabolism. Nutrients. 2013;5:2457-74.

59. Jackson B, Dietz S, Wightman R. Fast-scan cyclic voltammetry of 5-hydroxytryptamine. Anal Chem. 1995;67:1115-20

60. Abdalla A, West A, Jin Y, Saylor R, Qiang B, Pena E, Linden D, Nijhout HF, Reed M, Best J, Hashemi P. Fast serotonin voltammetry as a versatile tool for mapping dynamic tissue architecture: I responses at carbon fibers describe local tissue physiology. J Neurochem. 2020;153:33-50.

61. Abdalla A, Atcherley C, Pathirathna P, Samaranayake S, Qiang B, Pena E, Morgan S, Heien M, Hashemi P. In vivo ambient serotonin measurements at carbon-fiber microelectrodes. Anal Chem. 2017;89:9703.

62. Saylor R, Hersey M, West A, Buchanan A, Berger S, Nijhout HF, Reed M, Best J, Hashemi P. In vivo hippocampal serotonin dynamics in male and female mice: Determining effects of acute escitalopram using fast scan cyclic voltammetry. Front Neurosci. 2019;. https://doi.org/10.3389/fnins .2019.00362.

63. Asikainen M, Deboer T, Porkka-Heiskanen T, Stenberg D, Tobler I. Sleep deprivation increases brain serotonin turnover in the djungarian hamster. Neurosci Lett. 1995;198:21-4.

64. Whitney A, Diehn M, Popper S, Alizadeh A, Boldrick J, Relman D, Brown P. Individuality and variation in gene expression patternsin human blood. PNAS. 2003:100:1896-901.

65. Ahmed M, Dhanasekaran A, Tong S, Wiseman F, Fisher E, Tybulewicz V, Gardiner K. Protein profiles in tc1 mice implicate novel pathway perturbations in the down syndrome brain. Hum Mol Genetics. 2013;22:1709-24.

66. Birmes $P$, Coppin D, Schmitt L, Lauque D. Serotonin syndrome: a brief review. Can Med Assoc J. 2003;168:1439-42.

67. Boyer E, Shannon M. The serotonin syndrome. N Engl J Med. 2005:352:1112-20.

68. Asberg M, Thoren P, Traskman L, Bertilsson L, Ringberger V. "serotonin depression" - a biochemical subgroup within the effective disorders. Science. 1976;191:478.

69. Asberg M, Traskman L, Thoren P. 5-hiaa in the cerebrospinal fluid a biochemical suicide predictor. Arch Gen Psychiatry. 1976;33:1193.

70. Dray A, Gonye T, Oakley N, Tanner T. Evidence for the existence of a raphe projection to the substantia nigra in rat. Brain Res. 1976;113:45.

71. Asberg M, Ringberger $V$, Sjoqvist $F$, Thoren P, Traskman L, Tuck J. Monoamine metabolites in cerebrospinal fluid and serotonin uptake inhibition during treatment with chlorimipramine. Clin Pharmacol Ther. 1977;21:201.

72. Hyttel J. Neurochemical characterization of a new potent and selective serotonin uptake inhibitor: Lu 10-171. Psychopharmacology. 1977:51:225.

73. Coppen A, Swade C, Wood K. Platelet 5-hydroxytryptamine accumulation in depressive illness. Clinica Chimica Acta. 1978;87:165.

74. Gottlieb P, Wandall T, Overo K. Initial, clinical trial of a new, specific 5-ht reuptake inhibitor, citalopram (lu 10-171). Acta psychiatrica Scandinavica. 1980;62:236. 
75. Blier P, DeMontigny C, Azzaro A. Modification of serotonergic and noradrenergic neurotransmissions by repeated administration of monoamine oxidase inhibitors: electrophysiological studies in the rat central nervous system. J Pharmacol Exp Ther. 1986;237:987.

76. Oldendorf W, Szabo J. Amino acid assignment to one of three bloodbrain barrier amino acid carriers. Am J Physiol. 1976;230:94-8.

77. Wurtman R, Hefti F, Melemed E. Precursor control of neurotransmitter synthesis. Pharmacol Rev. 1981;32:315-50.

78. Fernstrom JD. Role of precursor availability in control of monoamine biosynthesis in brain. Physiol Rev. 1983;63:484-546.

79. Hood S, Bell C, Nutt D. Acute tryptophan depletion, part i: Rationale and methodology. Aust N J Z Psychiatry. 2005;39:558-64.

80. Fernstrom MH, Fernstrom JD. Brain tryptophan concentrations and serotonin synthesis remain responsive to food consumption after the ingestion of sequential meals. Am J Clin Nutr. 1995;61:312-9.

81. Holmes J, Lau T, an Fernandez-Novel N, Hersey RS, , M., Hampel, D.K.L., Horschitz, S., Reed, M., Nijhout, H., Koch, P., Hashemi, P.: Human induced pluripotent stem cell-derived serotonin neurons with biophysical and chemical functionality, submitted (2020)

82. Glaeser BS, Maher TJ, Wurtman RJ. Changes in brain levels of acidic, basic, and neutral amino acids after consumption of single meals containing various proportions of protein. J Neurochem. 1983;41:1016-21.

83. Nasset ES, Heald FP, Calloway DH, Margen S, Scheeman P. Amino acids in human blood plasma after single meals of meat, oil, sucrose, and whiskey. J Nutr. 1979;109:621-30.

84. Pecins-Thompson M, Brown N, Kohama S, Bethea C. Ovarian steroid regulation of tryptophan hydroxylase mrna expression in rhesus macaques. J Neurosci. 1996;16:7021-9.

85. Hiroi R, Neumaier J. Estrogen decreases 5-ht1b autoreceptor mrna is selective subregions of rat dorsal raphe nucleus: inverse association between gene expression and anxiety behavior in the open field. J Neurosci. 2009;158:456-64.

86. Karpinski M, Mattina G, Steiner M. Effect of gonadal hormones on neurotransmitters implicated in the pathophysiology of obsessive-compulsive disorder: Acritical review. Neuroendocrinology. 2017;105:1-16.

87. Hashemi P, Dankowski E, Wood K, Ambrose R, Wightman R. In vivo electrochemical evidence for simultaneous 5-ht and histamine release in the rat substantia nigra pars reticulata following medial forebrain bundle stimulation. J Neurochem. 2011;118:749-59.
88. Schlicker E, Betz R, Gothert M. Histamine h3 receptor-mediated inhibition of serotonin release in the rat brain cortex. Naunyn Schmiedebergs Arch Pharmacol. 1988;337:588.

89. Threlfell S, Cragg S, Kallo I, Turi G, Coen C, Greenfield S. Histamine h3 receptors inhibit serotonin release in substantia nigra pars reticulata. J Neurosci. 2004;24:8704.

90. Selim K, Kaplowitz N. Hepatotoxicity of psychotropic drugs. Hepatology. 1999;29:1347-51.

91. Weale M, Smith A, Gatriz F, Fletcher B, Thomas M, Bradman N, Goldstein D. Population genetic structure of variable drugresponse. Nat Genetics. 2001;29:265-9.

92. Cho Y-T, Yang C-W, Chu C-Y. Drug reaction with eosinophilia and systemic symptoms (dress): An interplay among drugs, viruses, and immune system. Int J Mol Sci. 2017;18:1-21.

93. Frazzetto $\mathrm{G}$. The drugs don't work for everyone. EMBO Reports. 2008;9:605-8.

94. Kirsch I, Deacon B, Huedo-Medina T, Scoboria A, Moore T, Johnson B. Initial severity and anti-depressant benefits: a meta-analysis of data submitted to the food and drug administration. PLOS Med. 2008;5:45.

95. Hvas A-M, Juul S, Bech P, Nexo E. Vitamin b6 level is associated with symptoms of depression. Psychother Psychosomatics. 2004;73:340-3.

96. Skarupski K, Tangney C, Li H, Ouyang B, Evans D, Morris M. Longitudinal association of vitamin b-6, folate, and vitamin b-12 with depressive symptoms among older adults over time. Am J Clin Nutr. 2010;92:330-5.

97. Sanchez-Villegas A, Doreste J, Schlatter J, Pla J, Bes-Rastrollo M, MartinezGonzolez M. Association between folate, vitamin b6 and vitamin b12 intake and depression in the sun cohort study. J Hum Nutr Diet. 2009;22:122-33.

98. Williams A-L, Cotter A, Sabina A, Girard C, Goodman J, Katz D. The role for vitamin b-6 as treatment for depression: a systematic review. Family Practice. 2005;22:532-7.

\section{Publisher's Note}

Springer Nature remains neutral with regard to jurisdictional claims in published maps and institutional affiliations.
Ready to submit your research? Choose BMC and benefit from:

- fast, convenient online submission

- thorough peer review by experienced researchers in your field

- rapid publication on acceptance

- support for research data, including large and complex data types

- gold Open Access which fosters wider collaboration and increased citations

- maximum visibility for your research: over $100 \mathrm{M}$ website views per year

At BMC, research is always in progress.

Learn more biomedcentral.com/submissions 